\title{
Grappling with homoplasy: taxonomic refinements and reassignments in the ant genera Camponotus and Colobopsis (Hymenoptera: Formicidae)
}

\author{
Philip S. Ward ${ }^{1}$, Brendon E. Boudinot ${ }^{1,2}$ \\ 1 Department of Entomology \& Nematology, University of California, Davis, One Shields Ave, Davis, CA 95616, USA; P. S. Ward* \\ 2 Friedrich-Schiller-Universität Jena, Institut für Zoologie und Evolutionsforschung, Erberstrasse 1, Jena, Thuringia, 07743, Germany; B. E. \\ Boudinot [boudinotb@gmail.com] \\ http://zoobank.org/6E3AE652-4AA5-49EF-B44D-C5B99C2AD0C6 \\ Corresponding author: Philip S. Ward (psward@ucdavis.edu)
}

Received 21 September 2020

Accepted 3 December 2020

Published 19 April 2021

Academic Editors Torben Riehl

Citation: Ward PS, Boudinot BE (2021) Grappling with homoplasy: taxonomic refinements and reassignments in the ant genera Camponotus and Colobopsis (Hymenoptera: Formicidae). Arthropod Systematics \& Phylogeny 79: 37-56. https://doi.org/10.3897/asp.79.e66978

\begin{abstract}
Camponotus and Colobopsis are widely distributed and species-rich genera in the ant tribe Camponotini. Molecular phylogenetic studies demonstrate that they are not sister taxa, but several lineages within each genus have converged to a remarkable degree, confounding the taxonomy of these ants. Based on multiple lines of evidence, including worker and male morphology, we demonstrate that: (1) three species of "Camponotus" belonging to the subgenus Myrmotemnus, including its type species, are in fact members of the genus Colobopsis; (2) four species previously assigned to Colobopsis belong to the subgenus Myrmamblys of Camponotus; and (3) three Nearctic taxa recently placed in Colobopsis are members of the genus Camponotus and closely related to Camponotus clarithorax. These taxonomic findings yield the following new or revived combinations: Colobopsis moeschi (comb. nov.), Colobopsis moeschi lygaea (comb. nov.), Colobopsis nutans (comb. nov.), Colobopsis nutans cleliae (comb. nov.), and Colobopsis reichenspergeri (comb. nov.); Camponotus apostemata (comb. nov.), Camponotus aurelianus (comb. rev.), Camponotus cavibregma (comb. nov.), Camponotus horrens (comb. rev.), Camponotus politae (comb. rev.), Camponotus trajanus (comb. rev.), and Camponotus yogi (comb. rev.). A further consequence is the following generic synonymy (senior synonym listed first): Colobopsis = Myrmotemnus syn. nov., and Camponotus = Dolophra syn. rev. At the species level, we argue that Camponotus apostemata and Camponotus cavibregma are junior synonyms (syn. nov.) of Camponotus yogi, and Camponotus quercicola is a junior synonym (syn. nov.) of Ca. laevigatus. Taxonomic comments are also provided on some members of the Camponotus reticulatus group, with Camponotus adustus (stat. nov.) and Ca. leucodiscus (stat. rev.) being recognized as distinct species rather than subspecies of $C a$. bellus. A male-based diagnosis of the Camponotini is provided, and differences between the males of Colobopsis and Camponotus are documented and illustrated for the first time. This study reveals new character systems of potential value to the systematics of these ants, including features of the male genitalia, and emphasizes the value of reciprocal illumination between phylogenomics and critical morphological analysis.
\end{abstract}

\section{Key words}

Convergent evolution, taxonomy, phylogeny, identification, morphology, male genitalia.

Copyright Philip S. Ward. This is an open access article distributed under the terms of the Creative Commons Attribution License (CC BY 4.0), which permits unrestricted use, distribution, and reproduction in any medium, provided the original author and source are credited. 


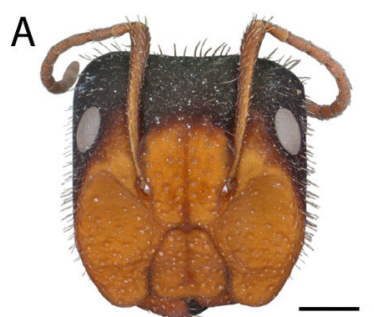

$\mathrm{E}$
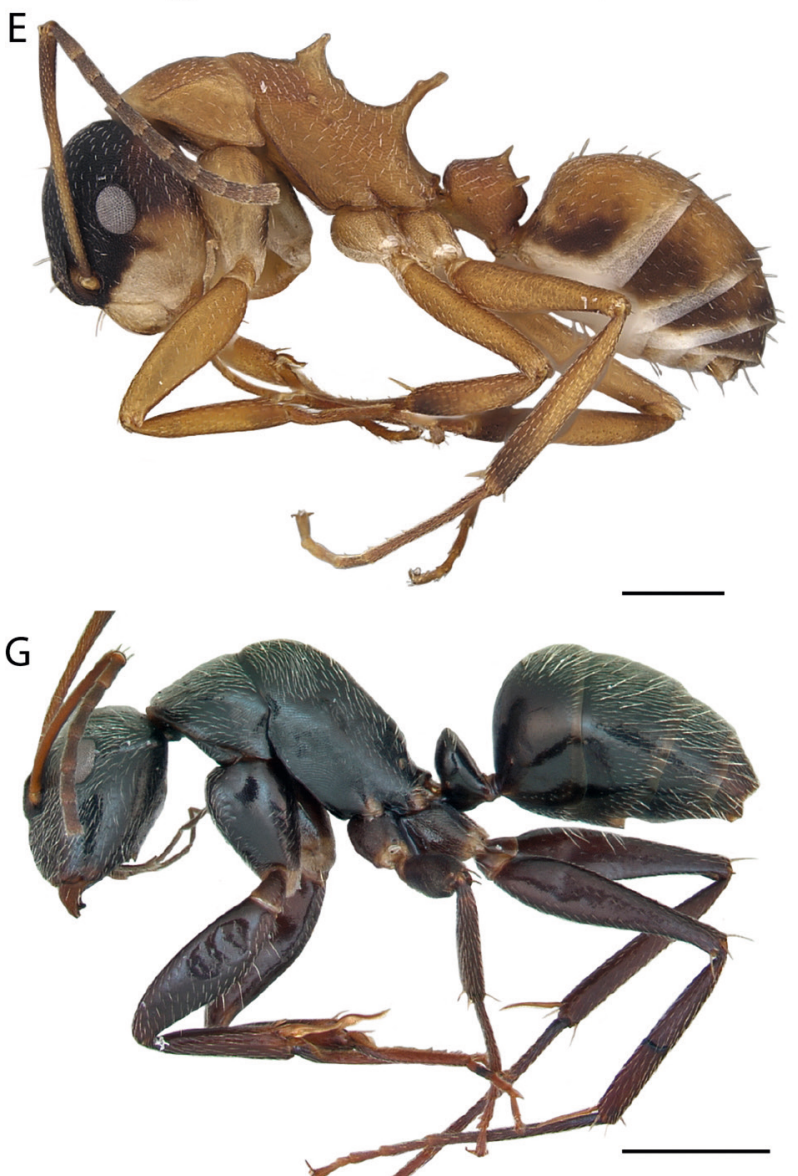
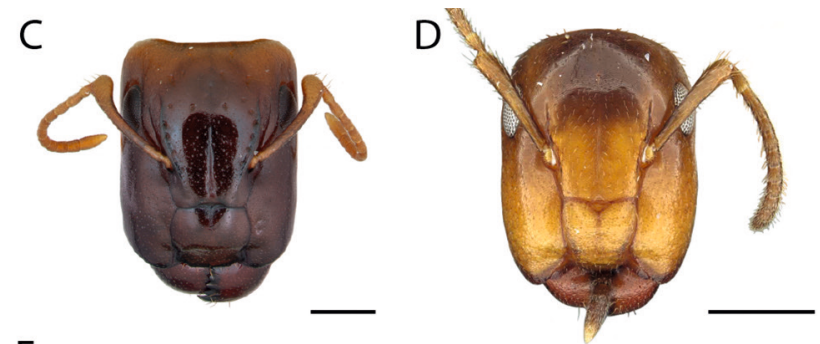

$\mathrm{F}$

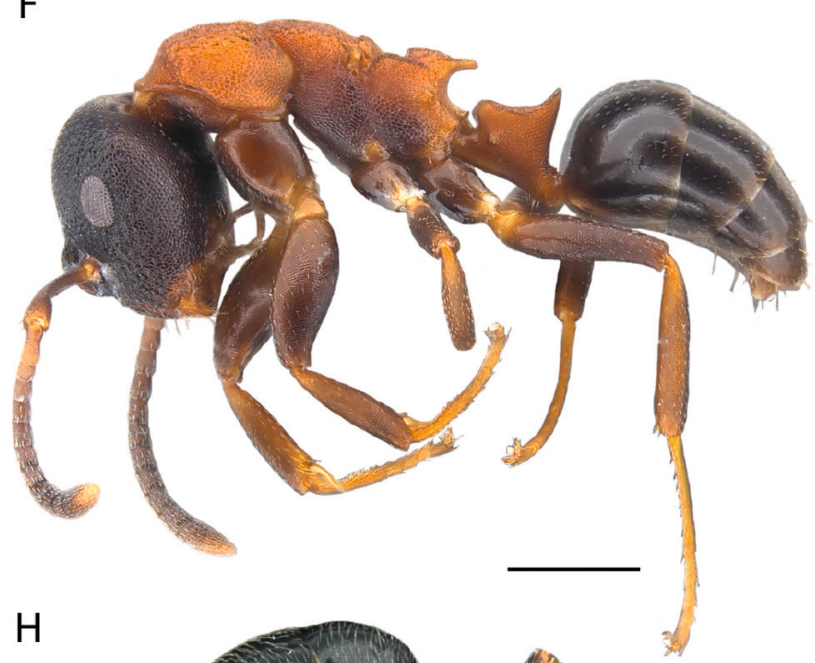

$\mathrm{H}$

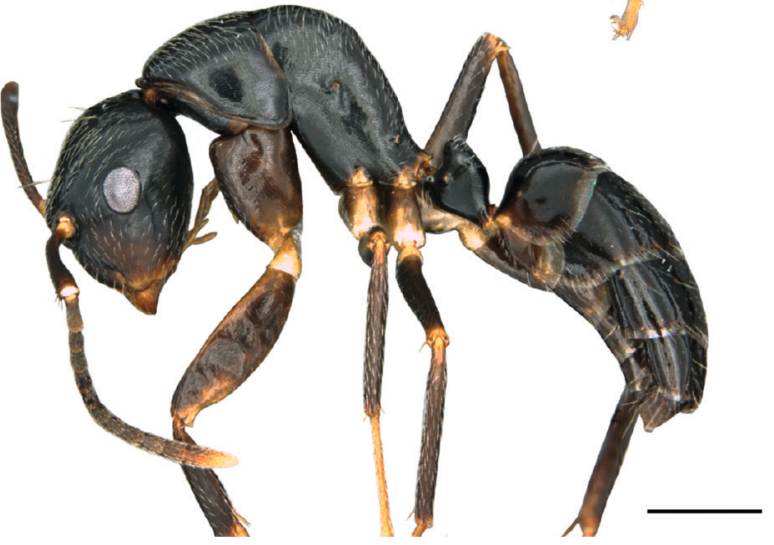

Figure 1. Examples of convergent evolution between Camponotus and Colobopsis: phragmosis in A and B; shiny elongate heads in $\mathrm{C}$ and $\mathrm{D}$; coarse sculpture and spination across tagmata in $\mathrm{E}$ and $\mathrm{F}$; and anteroposteriorly compressed and dorsally bulging mesosomata in G and H. Scale bars: $0.5 \mathrm{~mm}$ for A-F, $1.0 \mathrm{~mm}$ for G, H. A: Camponotus ulcerosus (CASENT0102784). B: Colobopsis obliqua (CASENT0103722). C: Camponotus claviscapus (JTLC00004447). D: Colobopsis markli (CASENT0911638). E: Camponotus heathi (CASENT0173421). F: Colobopsis dentata (CASENT0177557). G: Camponotus helleri (CASENT0173421), dorsal pilosity of body omitted. H: Colobopsis schmeltzi (CASENT0180467), dorsal pilosity of body omitted. Images from AntWeb (www.antweb. org); photographers April Nobile (A-C, G), Zach (Ziv) Lieberman (D), Shannon Hartman (E), Eli Sarnat (F), Evan Economo (H).

\section{Introduction}

Evolution is a heterogeneous process, occurring at variable rates in different lineages (Simpson 1953) and across different body structures (Hennig 1957). In hyperdiverse groups, such as ants, we find evidence for varying degrees of divergence from ancestral conditions. Large ant clades often contain a mixture of slower-evolving species that appear to have retained many original characteristics as well as highly divergent taxa that have evolved to the point where certain ancestral features are lost or indiscernible. Examples of this pattern include the "army ants" within the subfamily Dorylinae (Borowiec 2019), numer- ous genera of the Ponerinae (Schmidt 2013, Schmidt and Shattuck 2014), and social parasites in the Myrmicinae (Rabeling et al. 2014, Ward et al. 2015, Prebus 2017). In addition to this variable rate of evolutionary divergence, ants also show a strong propensity for convergent evolution of certain features in the worker caste, particularly with respect to defensive traits such as spines (Blanchard and Moreau 2017), morphology of the major worker (Hölldobler and Wilson 1990), and chemical weaponry (Hermann and Blum 1981). These evolutionary dynamics pose considerable challenges to ant systematics and, in 
particular, to the establishment of a ranked, phylogenetic classification (Ward 2011).

The two ant genera that are the subject of this paper, Camponotus Mayr and Colobopsis Mayr, exemplify this situation. The latter genus was established for those taxa whose major workers have markedly truncate (phragmotic) heads, used for blocking nest entrances (Mayr 1861). As species of Camponotus were discovered with similar phenotypes, however, the morphological justification for retention of the two genera appeared to weaken (Fig. 1). Eventually, Colobopsis was treated as a subgenus of Camponotus (e.g., Emery 1925, Bolton 2003). Recent molecular studies, employing UCE (ultra-conserved element) phylogenomic data, have demonstrated that Colobopsis is a phylogenetically distinct group, considerably distant from Camponotus, and sister to all other members of the tribe Camponotini (Blaimer et al. 2015). As a consequence, Colobopsis was resurrected as an independent genus, and 94 species were transferred from Camponotus to Colobopsis (Ward et al. 2016). Attempts to produce a simple worker-based diagnosis of both genera proved to be difficult, however, because of the large amount of variation observed in both clades, compounded by a confusing blend of convergent and divergent evolution.

Here we provide evidence that additional changes are needed to the taxonomy of these two genera. Specifically, certain species that are currently placed in Camponotus in fact belong to Colobopsis, and vice-versa. In this paper we justify these changes, clarify the species-level taxonomy of several taxa, and document, for the first time, diagnostic features of male Camponotini and differences between males of the two genera.

\section{Materials and methods}

\subsection{Methods}

This study is based on direct examination of specimens in collections, scrutiny of images on AntWeb (https://www. antweb.org), AntWiki (https://www.antwiki.org), and MCZbase (https://mczbase.mcz.harvard.edu), and interrogation of the original taxonomic literature. Images of male genitalia were taken using a JVC KY-F57U digital camera mounted on a Leica MZ 16A microscope, with resultant Z-stacks processed via Auto-Montage Pro (Synoptics Ltd., Cambridge, England), Adobe Photoshop 2020, and Adobe Illustrator 2020 (Adobe Systems Inc., California, USA).

\subsection{Terminology}

Terminology was used from the following sources: cranium (Richter et al. 2019, 2020), worker mesosoma (Liu et al. 2019), alate mesosoma (Boudinot 2015), wing venation (Brown and Nutting 1950), genitalia (Boudinot 2018), setational stature (Wilson 1955), and sculpture (Harris 1979). Genitalic term equivalencies among key works are as follows (see also Boudinot (2013) and references withi cited studies): cupula (= basal ring of Snodgrass (1941, 1957)), gonopod (= gonopodites in the strict sense, parameres of Snodgrass (1941, 1957), latimeres of Schulmeister (2001), stipites of Kempf (1956), stipes of Birket-Smith (1981)), gonocoxa (= gonocoxite in the strict sense, basimere of Snodgrass (1957), gonostipes of Schulmeister (2001)), gonostylus (= telomere or harpago of Snodgrass (1957), harpe of Schulmeister (2001)), volsella (= volsella), cuspis (= cuspis or distivolsella), gonapophysis (= digitus of Snodgrass (1941, 1957); Schulmeister (2001)), penial sclerite (= aedeagal sclerite of Snodgrass (1941, 1957), sagitta of Snodgrass (1957), penisvalva of Schulmeister (2001)).

\subsection{Morphometrics}

The following metric measurements and indices are employed for workers (see also Ward et al. 2016):

HW Head width: maximum width of head, excluding the eyes.

HL Head length: midline length of head from the anterior clypeal margin to a line drawn across the posterior margin of the head (medial indentations on either margin do not decrease length).

SL Scape length: length of first antennal segment, excluding the basal constriction.

WL Weber's length: length of mesosoma, taken in lateral view from the anterior margin of the pronotum, excluding the pronotal collar, to the posteroventral extremity of the metapleuron.

ASM Minimum distance between the antennal sclerites (inter-torular distance)

CLW Clypeus width: width of clypeus, taken at the anterior tentorial pits.

CLL Clypeus length: maximum measurable length of clypeus, taken along the midline, in an anterodorsal view, from a line drawn across posterior margin to a line across the anterior margin (medial indentations on either margin do not decrease length).

\subsection{Repositories}

AMNH American Museum of Natural History, New York, USA

BEBC Brendon E. Boudinot collection, University of California, Davis, California, USA

BMNH Natural History Museum, London, UK

CASC California Academy of Sciences, San Francisco, California, USA

CPDC Centro de Pesquisas do Cacau, Itabuna, Bahia, Brazil

CSCA California State Collection of Arthropods, Sacramento, California, USA

DZUP Coleção Entomológica Padre Jesus Santiago Moure, Universidade Federal do Paraná, Curitiba, Paraná, Brazil 
INBC Instituto Nacional de Biodiversidad, Heredia, Costa Rica

INPA Instituto Nacional de Pesquisas da Amazônia, Manaus, Amazonas, Brazil

JTLC John T. Longino collection, University of Utah, Salt Lake City, Utah, USA

LACM Natural History Museum of Los Angeles County, California, USA

MCZC Museum of Comparative Zoology, Harvard University, Cambridge, Massachusetts, USA

MHNG Muséum d'Histoire Naturelle, Geneva, Switzerland

MLBC Marek L. Borowiec collection, University of Idaho, Moscow, Idaho, USA

MSNG Museo Civico di Storia Naturale "Giacomo Doria", Genova, Italy

MZSP Museu de Zoologia da Universidade de São Paulo, São Paulo, Brazil

NHMW Naturhistorisches Museum, Vienna, Austria

PSWC Philip S. Ward collection, University of California, Davis, California, USA

UCDC Bohart Museum of Entomology, University of California, Davis, California, USA

USNM National Museum of Natural History, Washington DC, USA.

\subsection{Camponotus species for which males were examined}

Camponotus (Camponotus) Mayr: Ca. americanus Mayr, Ca. chromaoides Bolton, Ca. herculeanus (Linnaeus), Ca. japonicus Mayr, Ca. laevissimus MacKay, Ca. modoc Wheeler, Ca. sp. nr. modoc, Ca. novaeboracensis (Fitch), Ca. pennsylvanicus (De Geer), Ca. quercicola M.R. Smith, Ca. saxatilis Ruszky, Ca. schaefferi Wheeler, Ca. vagus (Scopoli).

Camponotus (Dendromyrmex) Emery: Ca. nitidior (Santschi).

Camponotus (Karavaievia) Emery: Ca. overbecki Viehmeyer.

Camponotus (Mayria) Forel: Ca. christi Forel, Ca. gibber Forel, Ca. immaculatus Forel, Ca. maculiventris Emery, Ca. manabo Rakotonirina \& Fisher, Ca. quadrimaculatus Forel, Ca. quadrimaculatus sellaris Emery, Ca. raina Rakotonirina \& Fisher, Ca. repens Forel.

Camponotus (Myrmamblys) Forel: Ca. bellus Forel, Ca. reticulatus sericellus Viehmeyer, Ca. thomasseti Forel.

Camponotus (Myrmaphaenus) Emery: Ca. hermanni Emery, Ca. novogranadensis Mayr, Ca. salvini Forel, $\mathrm{Ca}$. indet.

Camponotus (Myrmentoma) Forel: Ca. anthrax Wheeler, Ca. bakeri Wheeler, Ca. clarithorax Creighton, cuauhtemoc Snelling, Ca. dalmaticus (Nylander), Ca. decipiens Emery, Ca. discolor (Buckley), Ca. essigi M.R. Smith, Ca. fallax (Nylander), Ca. hyatti Emery, Ca. lateralis (Olivier), Ca. nearcticus Emery, Ca. rectithorax Forel, Ca. sayi Emery, Ca. cf. sayi.

Camponotus (Myrmepinotus) Santschi: Ca. edmondi André, Ca. ethicus Forel, Ca. robustus Roger.

Camponotus (Myrmespera) Santschi: Ca. emarginatus Emery.

Camponotus (Myrmeurynota) Forel: Ca. augustei Wheeler \& Mann, Ca. linnaei Forel.

Camponotus (Myrmobrachys) Forel: Ca. abscisus Roger, Ca. brettesi Forel, Ca. brevis Forel, Ca. cameranoi Emery, Ca. cuneidorsus Emery, Ca. dimorphus Emery, Ca. excisus Mayr, Ca. planatus Roger,
Ca. senex (F. Smith), Ca. textor Forel, Ca. trapezoideus Mayr, Ca. indet.

Camponotus (Myrmocladoecus) Wheeler: Ca. bidens Mayr, Ca. bispinosus Mayr, Ca. cf. bispinosus, Ca. mucronatus Emery, Ca. planus F. Smith, Ca. raphaelis Forel, Ca. rectangularis Emery, Ca. cf. sanctaefidei.

Camponotus (Myrmonesites) Emery: Ca. putatus Forel, Ca. reaumuri Forel.

Camponotus (Myrmophyma) Forel: Ca. dromedaries Forel.

Camponotus (Myrmopiromis) Wheeler: Ca. darwinii Forel, Ca. descarpentriesi Santschi, Ca. detritus Emery, Ca. fulvopilosus (De Geer), Ca. madagascarensis Forel, Ca. niveosetosus Mayr, Ca. voeltzkowii Forel.

Camponotus (Myrmoplatypus) Santschi: Ca. banghaasi Emery.

Camponotus (Myrmopsamma) Forel: Ca. mystaceus Emery.

Camponotus (Myrmopytia) Emery: Ca. imitator Forel, Ca. longicollis Rasoamanana et al.

Camponotus (Myrmosericus) Forel: Ca. auropubens Forel, Ca. cruentatus (Latreille), Ca. micans (Nylander), Ca. indet.

Camponotus (Myrmosphincta) Forel: Ca. sexguttatus (Fabricius), Ca. urichi sculnus Forel.

Camponotus (Myrmostenus) Emery: Ca. mirabilis Emery.

Camponotus (Myrmothrix) Forel: Ca. atriceps (F. Smith), Ca. cf. cingulatus, Ca. floridanus (Buckley), Ca. renggeri Emery.

Camponotus (Myrmotrema) Forel: Ca. bayeri Forel, Ca. grandidieri Forel.

Camponotus (Orthonotomyrmex) Ashmead; Ca. mayri Forel.

Camponotus (Paramyrmamblys) Santschi: Ca. ostiarius Forel.

Camponotus (Phasmomyrmex) Stitz: Ca. aberrans Mayr.

Camponotus (Pseudocolobopsis) Emery: Ca. alboannulatus nessus Forel, Ca. claviscapus Forel, Ca. curviscapus Emery, Ca. macilentus F. Smith, Ca. macrocephalus Emery, Ca. indet.

Camponotus (Tanaemyrmex) Ashmead: Ca. aegyptiacus Emery, Ca. aethiops (Latreille), Ca. cf. aethiops, Ca. ager F. Smith, Ca. albicoxis Forel, Ca. angusticollis (Jerdon), Ca. baldaccii Emery, Ca. bonanensis luteolus Emery, Ca. carin tipunus Forel, Ca. castaneus (Latreille), Ca. conspicuus sharpi Forel, Ca. conspicuus zonatus Emery, Ca. distinguendus (Spinola), Ca. dufouri Forel, Ca. dumetorum Wheeler, Ca.fedtschenkoi Mayr, Ca.festinatus (Buckley), Ca. foleyi fezzanensis Bernard, Ca. foleyi grasi Bernard, Ca. foleyi pseudocompressus Özdikmen, Ca. gouldi Forel, Ca. hildebrandti Forel, Ca. hova fulvus Emery, Ca. inaequalis Roger, Ca. irritans (F. Smith), Ca. kubaryi Mayr, Ca. latebrosus (Walker), Ca. maccooki Forel, Ca. maculatus (Fabricius), Ca. maritimus Ward, Ca. morosus (F. Smith), Ca. nitens Mayr, Ca. obreptivus Forel, Ca. ocreatus Emery, Ca. polymorphicus Mackay et al., Ca. punctulatus Mayr, Ca. cf. punctatulus, Ca. reburrus Mackay, Ca. roeseli Forel, Ca. sansabeanus (Buckley), Ca. semitestaceus Snelling, Ca. socius Roger, Ca. strangulatus Santschi, Ca. cf. substitutus, Ca. tortuganus Emery, Ca. variegatus ambonensis Karavaiev, Ca. vicinus Mayr.

Camponotus (unplaced to subgenus): Ca. alamaina Rakotonirina et al., Ca. armstrongi McAreavey.

\subsection{Colobopsis species for which males were examined}

Colobopsis clerodendri Emery, Co. conithorax (Emery), Co. cylindrica group spp., Co. dentata Mayr, Co. etiolata (Wheeler), Co. gasseri Forel, Co. impressa Roger, Co. leonardi (Emery), Co. macrocephala 
(Erichson), Co. moeschi (Forel), Co. moeschi lygaea (Viehmeyer), Co. papago (Creighton), Co. polynesica (Emery), Co. obliqua (M. R. Smith), Co. quadriceps (F. Smith), Co. schmeltzi (Mayr), Co. severini (Forel), Co. sommeri Forel, Co. truncata (Spinola), Co. vitrea group sp. indet., Colobopsis spp. indet. (Mexico, Papua New Guinea, Thailand, USA, Vanuatu).

Species evaluated solely from the literature: Co. aruensis (Karavaiev) [Klimes \& McArthur (2014)], Co. badia (F. Smith) [Laciny et al. (2018)], Co. explodens Laciny \& Zettel [Laciny et al. (2018)], Co. rotunda (Klimes \& McArthur) [Klimes \& McArthur (2014)].

\section{Results}

\subsection{New generic combinations}

In effecting these changes in generic assignment, we are guided by the differences in worker morphology uncovered in Ward et al. (2016), which are corroborated by character differences in the larvae and pupae, and by molecular phylogenetic data (Wernegreen et al. 2009, Blaimer et al. 2015, Clouse et al. 2015). In general, minor workers of Colobopsis can be distinguished from those of Camponotus by their more widely separated antennal insertions (ASM/HW 0.36-0.47, versus ASM/HW 0.22-0.35 in Camponotus), placement of those antennal insertions at about midlength of the frontal carinae (farther forward in Camponotus), and a relatively narrow, subquadrate clypeus (Ward et al. 2016). Exceptions occur, however, most notably among the Colobopsis species in New Caledonia and Fiji-where Camponotus is not well represented-and in the Colobopsis cylindrica group. The taxa in this paper that are subject to taxonomic reassignment are not members of the Co. cylindrica group nor part of the exceptional Pacific island radiations.

\subsubsection{Transfers from Camponotus to Colobopsis}

The Camponotus subgenus Myrmotemnus Emery currently contains five nominal species and two subspecies, all restricted to the Indomalayan region. The worker caste is characterized by having a strongly impressed metanotal groove, raised dorsal face of the propodeum, and compound eyes placed in a relatively posterior position on the head (Emery 1925, Santschi 1926). Examination of the type species of this subgenus, $\mathrm{Ca}$. moeschi Forel, shows that it is clearly a species of Colobopsis: the antennal insertions are well separated (ASM/HW 0.43-0.44, ASM/CLW 0.82-0.89) and occur at about the midlength of the frontal carinae, and the clypeus is relatively narrow (CLW/CLL 1.12) (Fig. 2A). This is observed in material collected recently in Sabah, Malaysia (CASENT0863455) and in a syntype worker from Sumatra illustrated on AntWeb (CASENT0910546). Accordingly, this species becomes Colobopsis moeschi (Forel) comb. nov., and Myrmotemnus is a junior synonym (syn. nov.) of Colobopsis.
Four of the other taxa that were placed in Camponotus (Myrmotemnus) also exhibit widely spaced antennal insertions and other features of Colobopsis and are hereby transferred to that genus: Colobopsis moeschi lygaea (Viehmeyer) comb. nov. (Fig. 2B), Co. nutans (Mayr) comb. nov. (Fig. 2C), Co. nutans cleliae (Santschi) comb. nov., and Co. reichenspergeri (Santschi) comb. nov. (Fig. 2D). Although we justify these changes based upon worker morphology, a male specimen of Co. moeschi lygaea (Fig. 11H, P, X) has the genital features characteristic of Colobopsis (see below). In addition, UCE (ultra-conserved element) phylogenomic data place this taxon in Colobopsis, close to Colobopsis vitrea (Ward, unpublished).

The two remaining species associated with Camponotus (Myrmotemnus) are retained in Camponotus. Camponotus hypoclineoides Wheeler has the antennal insertions relatively closely positioned (ASM/HW 0.33) and anterior to the mid-length of the frontal carinae (Fig. 3A). It is reassigned to the subgenus Karavaievia Emery, where it was placed by Santschi (1926: 601). This is also consistent with Wheeler's (1919) assertion that Ca. hypoclineoides is related to $\mathrm{Ca}$. dolichoderoides Forel, a current member of subgenus Karavaievia (Dumpert et al. 2006). Camponotus impressilabris Stitz also shows the frontoclypeal configuration typical of Camponotus (ASM/HW 0.29, ASM/CLW 0.63) (Fig. 3B), and is here assigned to Camponotus subgenus Orthonotomyrmex Ashmead, based on structural features shared with other species in that subgenus: a bidentate propodeum, nodiform petiole, and matte integument.

\subsubsection{Transfers from Colobopsis to Camponotus}

The Camponotus subgenus Myrmamblys Forel contains a diverse array of species, found mostly in the Indo-Australian region (Emery 1925, Bolton 1995). The workers are small to medium in size, and worker polymorphism is pronounced. The soldiers usually have the head longer than wide, and often obliquely truncate (with the truncation encompassing the entire clypeus), while the head of the minor worker is broader with more rounded sides. Within this subgenus, Emery (1925) recognized a group of species that he called the Ca. reticulatus group, and which he characterized as follows: mesosoma dorsum of worker continuous or interrupted, but not constricted in front of the propodeum; and dorsum of propodeum often saddle-shaped in profile but neither marginate nor compressed. Some members of the $\mathrm{Ca}$. reticulatus group superficially resemble Colobopsis, as a consequence of their small size, propodeal profile, and soldiers with partially phragmotic heads. We have discovered the following four species, currently placed in Colobopsis, which actually belong to Camponotus (Myrmamblys) and which have affinities to the $\mathrm{Ca}$. reticulatus group. Previous molecular work has confirmed that the $\mathrm{Ca}$. reticulatus group is part of Camponotus (Wernegreen et al. 2009, Blaimer et al. 2015).

Camponotus (Myrmamblys) horrens Forel (comb. rev.) (Fig. 4A, B) has closely placed antennal insertions (ASM/ HW 0.25) and a broad clypeus, which preclude its place- 

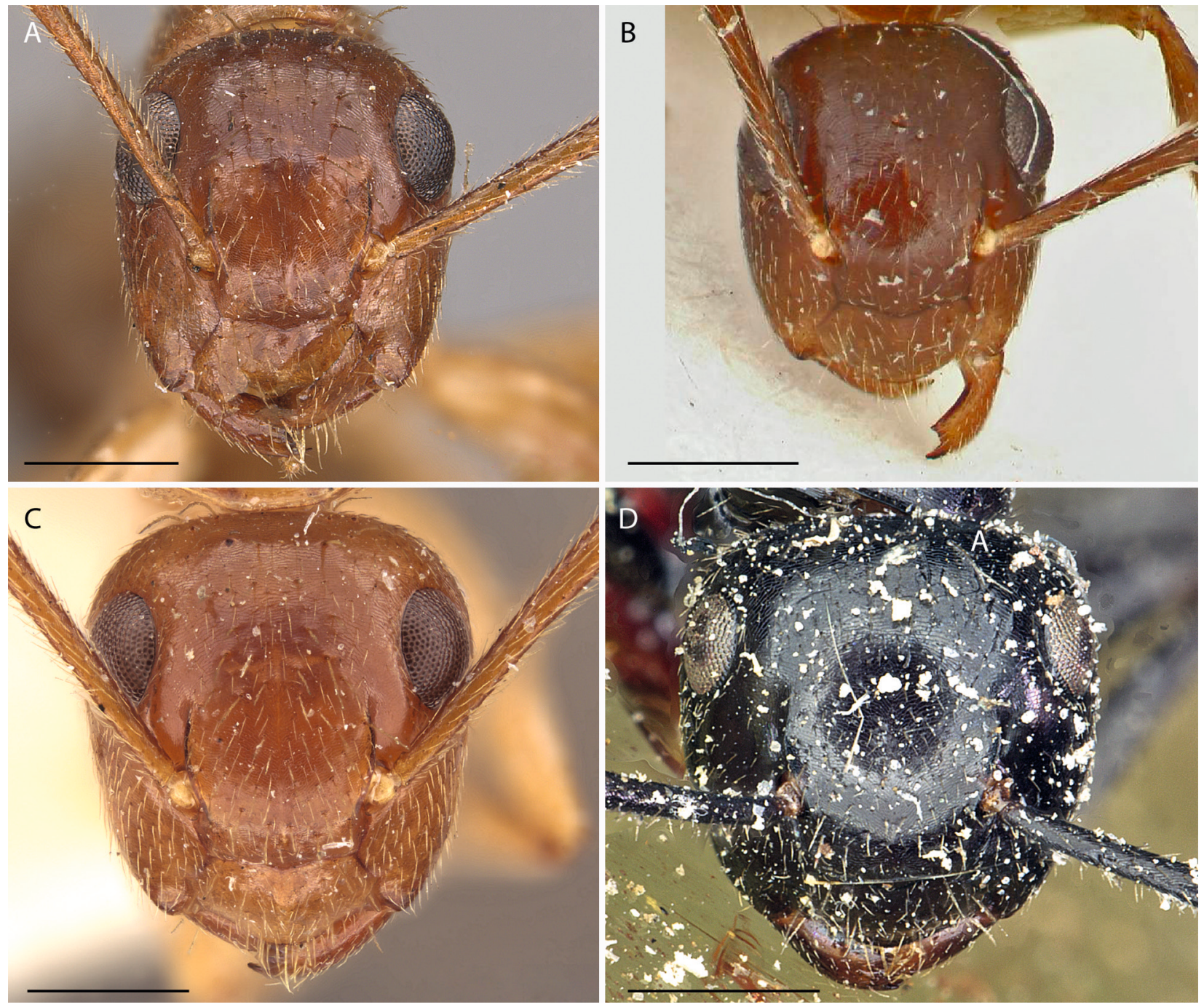

Figure 2. Representatives of former Camponotus subgenus Myrmotemnus, now in Colobopsis; full-face (dorsal) views of head of minor worker, scale bars $=0.5 \mathrm{~mm}$. A: Syntype worker of Colobopsis moeschi (CASENT0910546). B: Syntype worker of Colobopsis moeschi lygaea (FOCOL2270). C: Holotype worker of Colobopsis nutans (CASENT0915604). D: Holotype worker of Colobopsis reichenspergeri (CASENT0911793). Images from AntWeb (www.antweb.org); photographers Will Ericson (A), Christiana Klingenberg (B), Daniela Lehner (C), and Zach (Ziv) Lieberman (D).
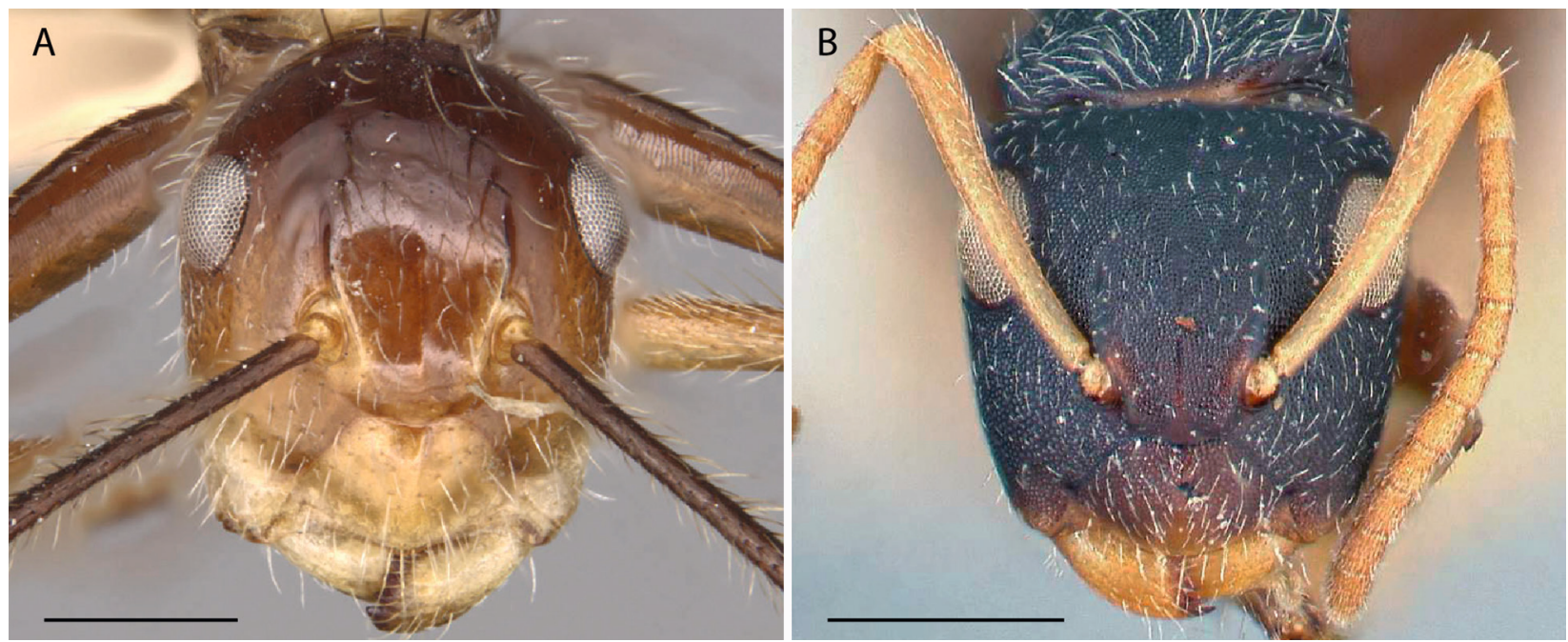

Figure 3. Representatives of former Camponotus subgenus Myrmotemnus, retained in Camponotus; full-face (dorsal) views of head of minor worker; scale bars $=0.5 \mathrm{~mm}$. A: Holotype worker of Camponotus hypoclineoides (MCZ-ENT00021520), image from MCZbase (Museum of Comparative Zoology, Harvard University, copyright President and Fellows of Harvard College). B: Syntype worker of Camponotus impressilabris (FOCOL2273), image from AntWeb (www.antweb.org); photographer Christiana Klingenberg. 

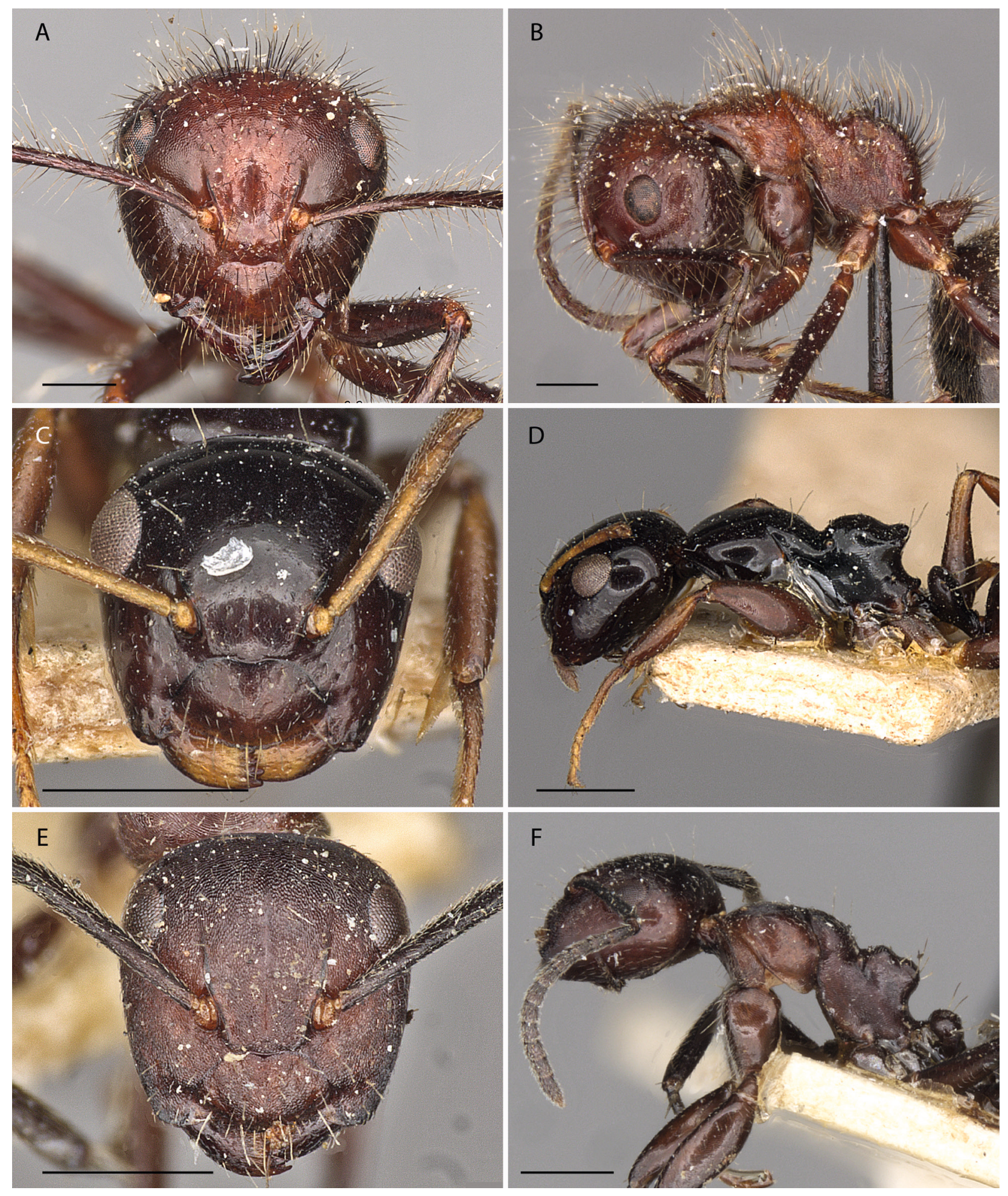

Figure 4. Taxa formerly in Colobopsis, now assigned to Camponotus (Myrmamblys); full-face (dorsal) views of head of minor worker (A, C, E) and lateral views of body (B, D, F); scale bars = $1.0 \mathrm{~mm}$. A, B: Syntype worker of Camponotus horrens (CASENT0910609). C, D: Syntype worker of Camponotus aurelianus (CASENT0910598). E, F: Syntype worker of Camponotus trajanus (CASENT0910612). Images from AntWeb (www.antweb.org); photographer Will Ericson.

ment in Colobopsis. Little is known about this curious species; Forel (1910) surmised that it is a mimic of Myrmicaria brunnea. Placement in the Camponotus reticulatus group is provisional.

Camponotus (Myrmamblys) politae (Wu \& Wang) (comb. rev.) was originally described in its own genus, Dolophra, later assigned to Camponotus (Bolton 1995), then to Camponotus subgenus Colobopsis (Bolton 2003), and finally to Colobopsis (Ward et al. 2016). The illustration of the worker head in the original publication ( $\mathrm{Wu}$ and Wang 1994: 36) indicates that this is a Camponotus species, given the closely approximated antennal insertions (ASM/HW 0.23) and broad clypeus. Moreover, the elongate nodiform petiole and the shape of the propodeum, 

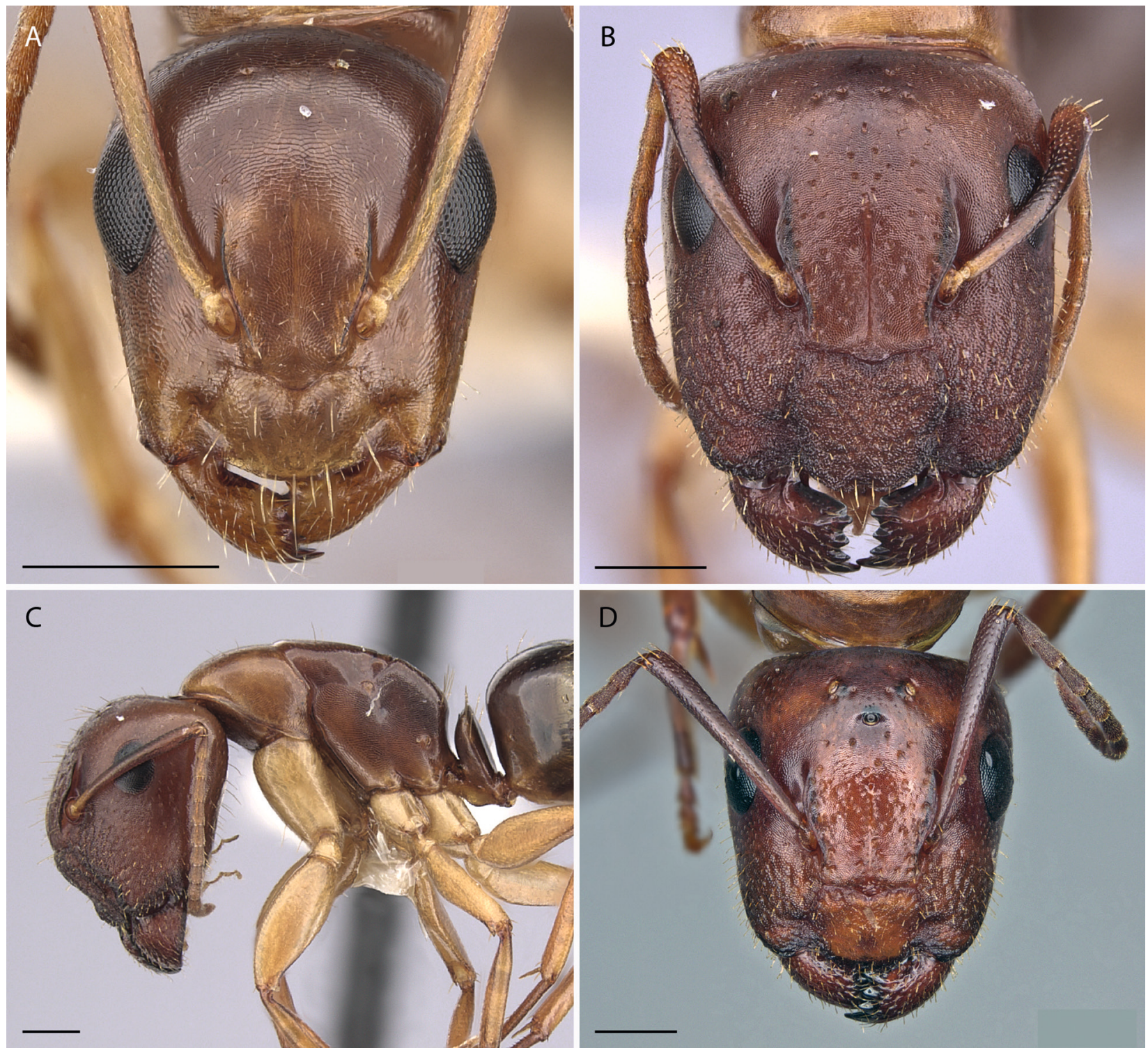

Figure 5. Camponotus yogi, full-face dorsal views of head (A, B, D) and lateral view of body (C); scale bars = $0.5 \mathrm{~mm}$. A: Minor worker (CASENT0249398). B, C: Major worker (CASENT0249399). D: Dealate queen (CASENT0923092). Images from AntWeb (www.antweb.org); photographers Will Ericson (A-C), and Wade Lee (D).

with concave dorsal and declivitous faces, place it close to Camponotus (Myrmamblys) bellus and related species, in the Ca. reticulatus group. Consequently, Dolophra again becomes a junior synonym of Camponotus (syn. rev.).

Similarly, the syntype workers of Camponotus (Myrmamblys) aurelianus Forel (comb. rev.) (Fig. 4C, D) and Camponotus (Myrmamblys) trajanus Forel (comb. rev.) (Fig. 4E, F) have a frontoclypeal structure (ASM/HW $\sim 0.34$ and $\sim 0.32$, respectively) and propodeal shape that place them in the Ca. reticulatus group, near $\mathrm{Ca}$. bellus .

Turning to the Nearctic fauna, there are three taxa recently assigned to Colobopsis by Mackay \& Mackay (2018) that are members of the genus Camponotus, and close to the nominate subgenus. One of these is Camponotus yogi Wheeler, long considered to be a bona fide Camponotus, which was transferred to Colobopsis on the basis of superficial similarity; it is here returned to Camponotus (comb. rev.). The major workers of $\mathrm{Ca}$. yogi have obliquely phragmotic heads (Fig. 5B, C), but these are quite unlike those of New World Colobopsis (Creighton and Snelling 1967). The minor workers are very similar to those of Camponotus clarithorax. These smaller workers of Ca. yogi (HW 0.98-1.22, WL 1.67-1.95) have the traits typical of Camponotus rather than Colobopsis, i.e., closely approximated antennal insertions (ASM/HW $0.30-0.34)$, that are placed anterior to the midlength of the frontal carinae, and a broad clypeus (Fig. 5A). Unlike Colobopsis, which has naked pupae, those of Camponotus yogi are enclosed in cocoons (Creighton and Snelling 1967) and the larvae lack the praesaepium, or ventral pocket, that is diagnostic of Colobopsis. Phylogenomic (UCE) data also support the placement of Ca. yogi in Camponotus, and show it to be closely related to $\mathrm{Ca}$. clarithorax (Ward, unpublished).

The other two taxa placed incorrectly in Colobopsis by Mackay \& Mackay (2018) were described as new species and are here transferred to Camponotus: Ca. apostemata (Mackay) (comb. nov.) and Ca. cavibregma (Mackay) 


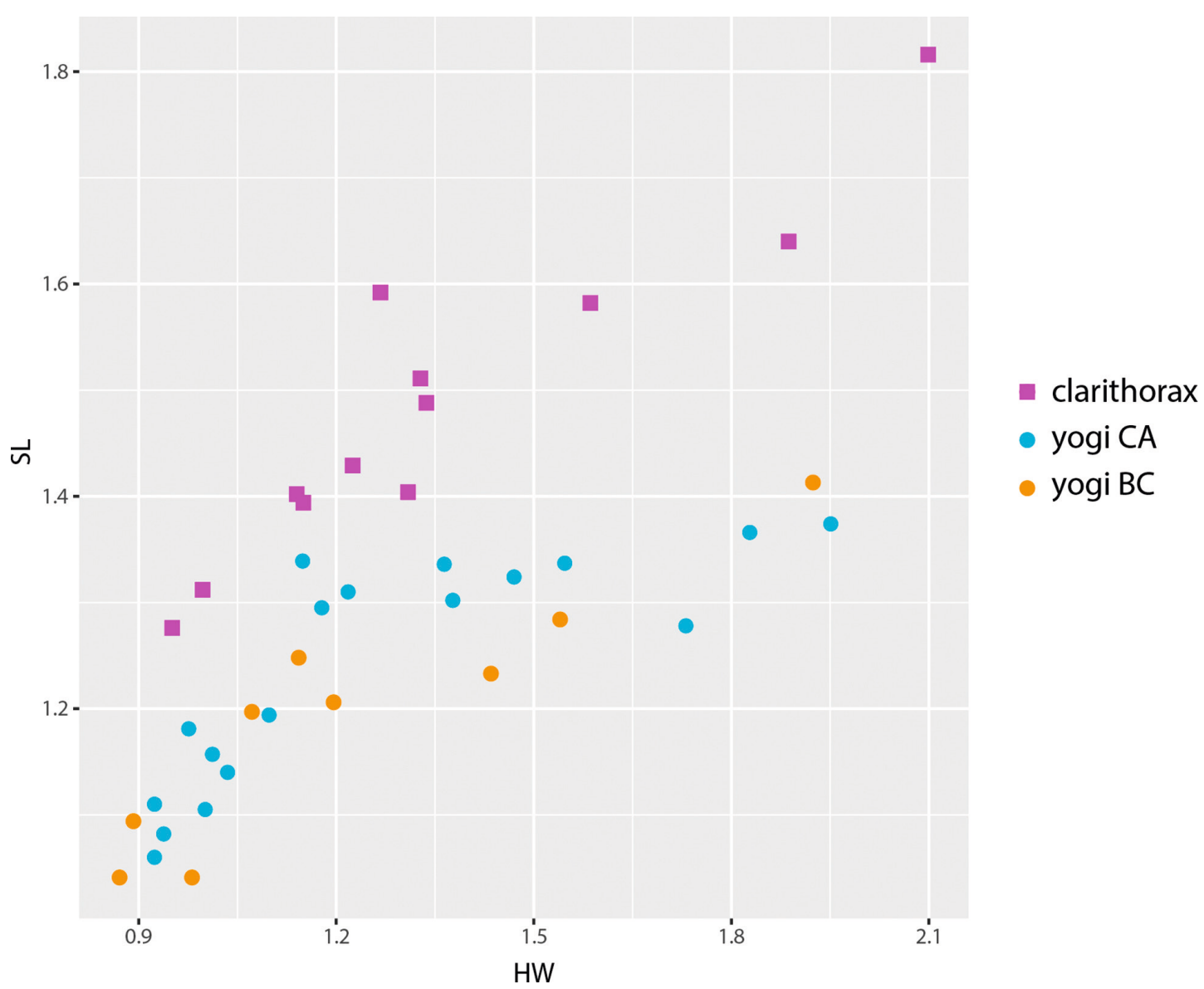

Figure 6. Plot of scape length (SL) against head width (HW) for workers of Camponotus clarithorax (n = 12) and Camponotus yogi $(\mathrm{n}=27)$. Samples of Camponotus yogi from northern Baja California $(\mathrm{BC})$ fall within the same cluster of points as those from California (CA).

(comb. nov.). These two are very similar to Camponotus yogi and, we argue below, are justifiably treated as junior synonyms of that species. All three names are here placed in the nominate subgenus of Camponotus.

\subsection{Species-level taxonomy}

\subsubsection{Camponotus yogi Wheeler}

Figs. 5, 6

Camponotus yogi Wheeler, 1915: 420. Two syntype workers, Point Loma, California, USA (P. Leonard) (AMNH) [examined via image supplied by Christine Lebeau].

Colobopsis apostemata Mackay, in Mackay and Mackay, 2018: 100. Holotype major worker, Tecate, Baja California, Mexico (LACM) [not examined]. Syn. nov.

Colobopsis cavibregma Mackay, in Mackay and Mackay, 2018: 107. Holotype dealate queen, Skinner Reservoir, Riverside Co., California, USA (T. Prentice) (LACM) [not examined]. Syn. nov.

Camponotus (Colobopsis) yogi Wheeler; Wheeler, 1917: 562. Placement in Camponotus (Colobopsis).

Camponotus (Myrmaphaenus) yogi Wheeler; Emery, 1925: 156. Placement in Camponotus (Myrmaphaenus).

Camponotus (Myrmaphaenus) yogi Wheeler; Creighton and Snelling, 1967. Taxonomic and biological notes.
Colobopsis yogi (Wheeler); Mackay and Mackay, 2018: 215. Combination in Colobopsis.

Camponotus yogi Wheeler; present study. Combination in Camponotus (comb. rev., see above).

Camponotus apostemata (Mackay); present study. Combination in Camponotus (comb. nov., see above).

Camponotus cavibregma (Mackay); present study. Combination in Camponotus (comb. nov., see above).

1. Based on the original description and figures (Mackay and Mackay 2018: 111-113), the holotype of Camponotus cavibregma appears to be simply a queen of Ca. yogi. Its supposedly distinctive feature - a concave genal area, free of the short spatulate hairs that are common on surrounding anterior regions of the head-is observed also in queens of $\mathrm{Ca}$. yogi (Fig. 5D). The description and illustrations of the paratype minor worker of Ca. cavibregma (Mackay and Mackay 2018: 109-111) similarly place it within the range of variation exhibited by minor workers of Ca. yogi.

Camponotus apostemata, described from a series of workers collected in northern Baja California (specimens from this series examined in LACM), is scarcely distinguishable from Camponotus yogi, and is here treated as part of the geographical variation of the latter species. The head of the major worker is a bit more strongly truncate than in populations farther north, but no consistent 
differences are seen in the minor workers. Johnson \& Ward (2002) referred to these and other samples of $C a$. yogi from Baja California as Camponotus sp. cf. yogi.

Camponotus yogi is closely related to $\mathrm{Ca}$. clarithorax Creighton. The major worker of the latter species lacks a pitted, obliquely truncate head, but is otherwise structurally similar. The two species can be distinguished by differences in scape and leg length, with $C a$. yogi having consistently shorter appendages than Ca. clarithorax (Fig. 6), although very small workers may be difficult to distinguish. The median clypeal notch or concavity is better developed, on average, in $\mathrm{Ca}$. clarithorax workers than in those of $\mathrm{Ca}$. yogi, a feature which led to the placement of Ca. clarithorax in the subgenus Myrmentoma, but neither species belongs in that subgenus. They are here treated as Camponotus (Camponotus) since genetic data indicate a fairly close relationship to other species in that subgenus (Wernegreen et al. 2009; Ward, unpublished). In addition to $C a$. clarithorax and $C a$. yogi, there are two other species in the Ca. yogi group: Ca. keiferi Wheeler, endemic to Isla Guadalupe, Mexico (and already placed in the nominate subgenus), and an undescribed species from the California Channel Islands (Ward, unpublished).

Camponotus yogi is endemic to California and northern Baja California, where it occurs in coastal sage scrub, chaparral, oak woodland, and oak-juniper woodland. Nests are located in dead branches or stumps of various plants, always near the ground and often extending into live plant tissue. Creighton \& Snelling (1967) reported this species nesting in live beetle-bored stems of Ericameria pinifolia, and tending pseudococcids in the stems.

\subsubsection{Camponotus laevigatus (F. Smith)}

Fig. 7A-D

Formica laevigata F. Smith, 1858: 55. Lectotype worker, California, United States $(\mathrm{BMNH})$ [examined via image on AntWeb: CASENT0903603]

Camponotus laevigatus (F. Smith); Roger, 1863: 5. Combination in Camponotus.

Camponotus (Camponotus) laevigatus (F. Smith); Forel, 1914: 266. Placement in Camponotus (Camponotus).

Camponotus (Camponotus) laevigatus (F. Smith); Mackay, 2019: 246. Lectotype worker designated.

Camponotus (Camponotus) quercicola M. R. Smith, 1954: 211. Holotype worker, Tanbark Flat, Los Angeles County, California (T. C. Lawrence) (USNM) [examined]. Syn. nov.

Camponotus quercicola M. R. Smith; Gadau et al., 1999. Description of male and queen. Biology and distribution.

1. Mackay (2019) discovered that the types of this species in $\mathrm{BMNH}$ - a syntype dealate queen and syntype major worker, the latter designated by him as lectotypedo not correspond to the species that has come to be known in the literature as Camponotus laevigatus. That species, given the new name Ca. laevissimus Mackay, is easily recognized by its shiny, iridescent blue-black integument and abundant and bright white standing pilosity on most of the body, including the scapes and tibiae
(Fig. 7E, F). The real Camponotus laevigatus is a shiny black species, with relatively sparse standing pilosity, inconspicuous pubescence, slender scape base, and ecarinate clypeus. Examination of the lectotype image (Fig. 7A, B) shows that Camponotus laevigatus is conspecific with Ca. quercicola, a widespread California species that nests in the trunks and branches of oak trees (Gadau et al. 1999) (Fig. 7C, D). Mackay (2019) claimed that Ca. laevigatus differs from $\mathrm{Ca}$. quercicola in having reduced pilosity on the head, but the lectotype is an old specimen in which the hairs are evidently abraded. Note the asymmetry in presence of hairs on the two sides of the head in the AntWeb image (e.g., short setae present on the left malar region but not on the right side) (Fig. 7A). Moreover, the amount of standing pilosity shows considerable variation in workers of $\mathrm{Ca}$. quercicola, including setation on the malar region (Smith 1954; Gadau et al. 1999). We have examined a large series of Camponotus quercicola from throughout California, and we find that the type of $\mathrm{Ca}$. laevigatus falls easily within the range of variation exhibited by this species. Mackay (2019: 321) also stated that the male and queen of $\mathrm{Ca}$. quercicola (now $\mathrm{Ca}$. laevigatus) are unknown, but this is incorrect: they were described and illustrated by Gadau et al. (1999) and compared with related species.

\subsubsection{Camponotus adustus Viehmeyer stat. $n$.}

Fig. $8 \mathrm{~A}, \mathrm{~B}$

Camponotus (Myrmamblys) bellus subsp. adustus Viehmeyer, 1916: 159. Holotype worker (by monotypy), Singapore (H. Overbeck) (ZMHB) [examined via image on AntWeb: FOCOL2281].

1. Ca. adustus was described by Viehmeyer (1916) as a subspecies of $\mathrm{Ca}$. bellus Forel, but examination of the original descriptions, images of types, and more recent material indicates that these two are distinct species. Camponotus bellus (syntype major worker, Amboina, Indonesia (Biró) [MHNG]; examined via image on AntWeb: CASENT0910513) has a matte integument and more abundant standing pilosity on the mesosoma, including the pronotum (Fig. 8C, D). In contrast, the body of $\mathrm{Ca}$. adustus is predominantly shiny and standing pilosity is sparse on the mesosoma, being restricted to a single pair of long setae on the mesonotum and one pair at the junction of the dorsal and declivitous faces of the propodeum (Fig. 8A, B). Moreover, the two taxa have been recorded co-occurring in Singapore and remaining distinct (Viehmeyer 1916).

In addition to the foregoing pilosity characteristics, the minor worker of $\mathrm{Ca}$. adustus has striking anterior and posterior protuberances on the dorsal face of the propodeum, and both the dorsal and declivitous faces are notably concave in lateral view (Fig. 8B). Under this general morphotype, however, there is a bewildering diversity of color forms whose taxonomic status is unclear. One of these, Ca. leucodiscus Wheeler, has also been treated as a subspecies of $C a$. bellus, and is here raised to species 

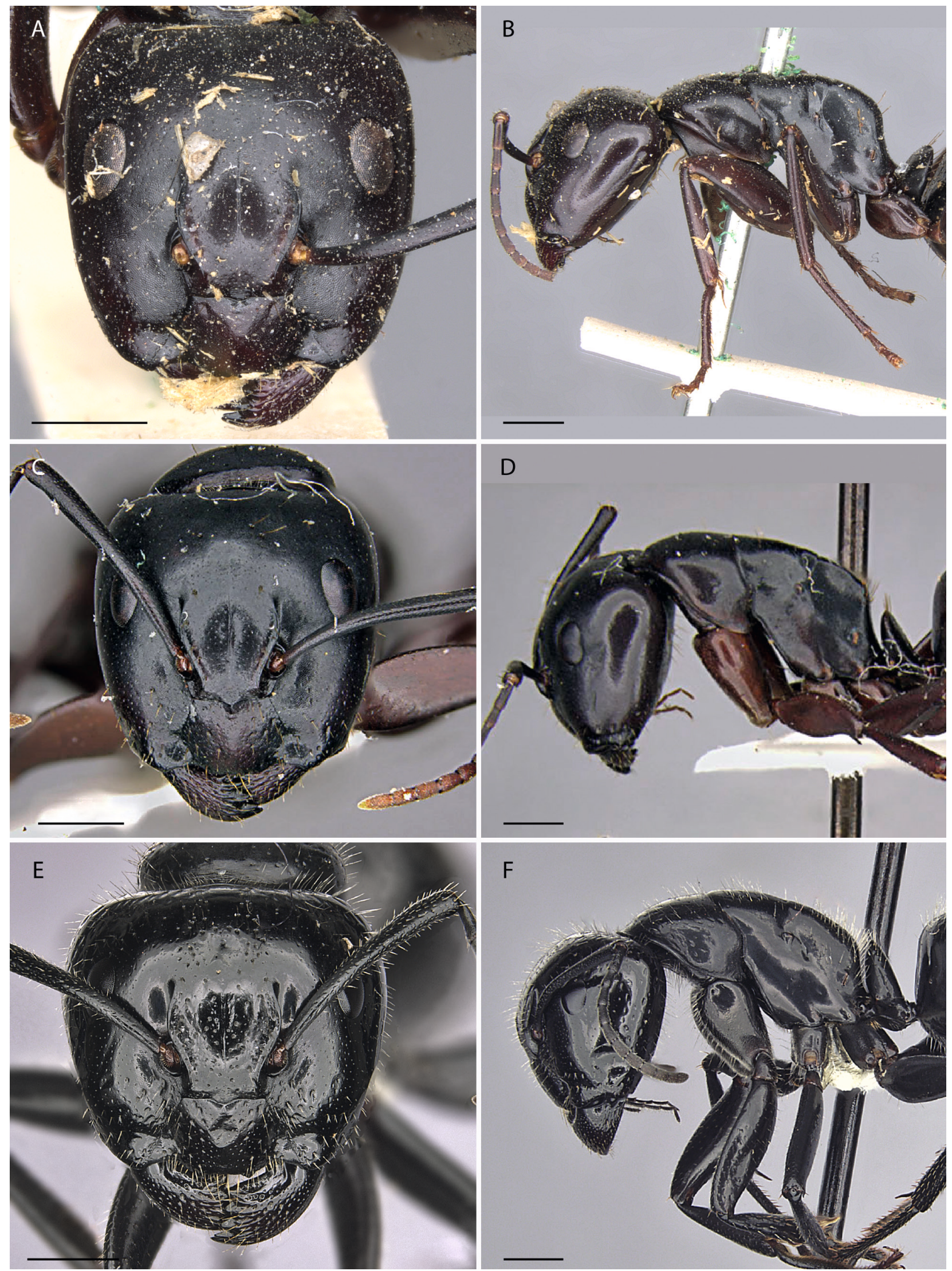

Figure 7. Camponotus workers, full-face (dorsal) views of head (A, C, E) and lateral views of body (B, D, F); scale bars = $1.0 \mathrm{~mm}$. A, B: Camponotus laevigatus, lectotype (CASENT0903603). C, D: Camponotus quercicola, paratype (MCZ-ENT00029334), image from MCZbase (Museum of Comparative Zoology, Harvard University, copyright President and Fellows of Harvard College). E, F: Camponotus laevissimus (CASENT0280010). Images A, B, E, F from AntWeb (www.antweb.org); photographer Will Ericson. 

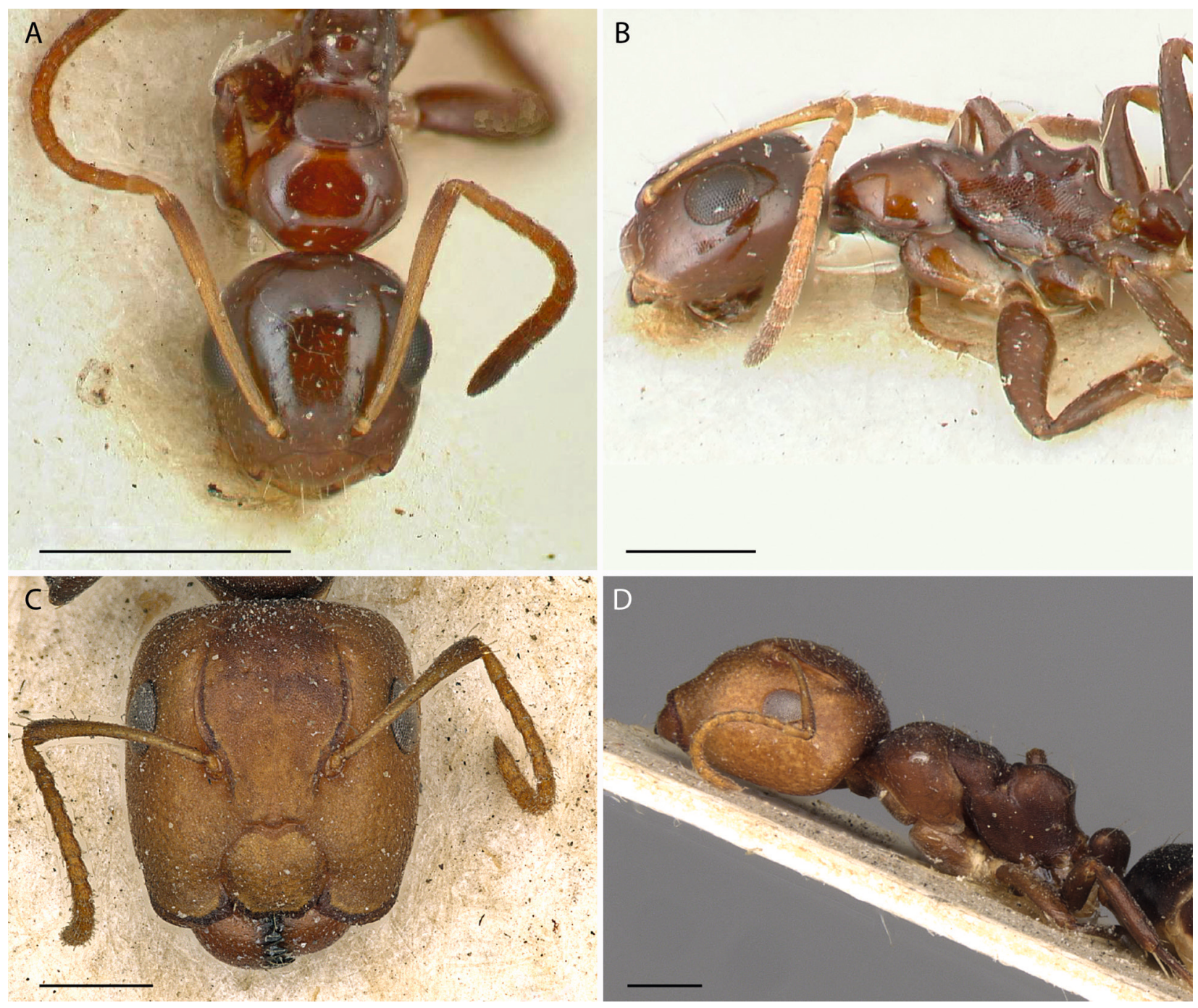

Figure 8. Camponotus workers, full-face (dorsal) views of head (A, C) and lateral views of body (D, E); scale bars $0.5 \mathrm{~mm}$. A, B: Camponotus adustus, holotype worker (FOCOL2281); scale bars $=0.5 \mathrm{~mm}$. C, D: Camponotus bellus, syntype major worker (CASENT0910513). Images from AntWeb (www.antweb.org); photographers Christiana Klingenberg (A, B), and Zach (Ziv) Lieberman $(C, D)$.

(below), but its relationship to $\mathrm{Ca}$. adustus remains to be clarified. The New Guinea species Camponotus weismanni Forel (syntype worker, Bismarck Archipelago; examined via image on AntWeb: FOCOL2297) might be a senior synonym of $\mathrm{Ca}$. adustus, but the worker propodeum has less well-developed protuberances and a correspondingly less concave dorsal surface in profile.

\subsubsection{Camponotus leucodiscus Wheeler stat. rev.}

Fig. 9

Camponotus (Colobopsis) leucodiscus Wheeler, 1919: 117. Holotype dealate queen (by monotypy), British North Borneo (E. B. Kershaw) (MCZC) [examined via image on MCZbase: MCZ-ENT00021564]

Camponotus (Colobopsis) leucodiscus; Wheeler, 1919: 118. Description of worker, soldier.

Camponotus (Myrmamblys) bellus leucodiscus; Emery, 1925: 138. Placement in Camponotus (Myrmamblys) and subspecies of $\mathrm{Ca}$. bellus.
1. Workers associated with Ca. leucodiscus (i.e., matching the striking black and white color pattern on the gaster of the holotype queen) lack the matte integument and pilosity of $\mathrm{Ca}$. bellus, and are instead shiny and with sparse pilosity, as described above for Ca. adustus. They apparently differ from workers of $\mathrm{Ca}$. adustus by the longer, lower petiole and by the color pattern on the gaster. Both taxa that are here elevated to species are part of a larger assemblage of ants in the Ca. reticulatus group that need comprehensive taxonomic study.

\subsection{Male characters of Camponotus and Colobopsis}

\subsubsection{Identification of male Camponotini}

Diagnosis. Camponotini are well-defined morphologically based on the female castes (Bolton 2003). Males are identifiable as Formicinae by their long scapes, the strongly oblique gonocoxal-gonostylar articulation, ab- 

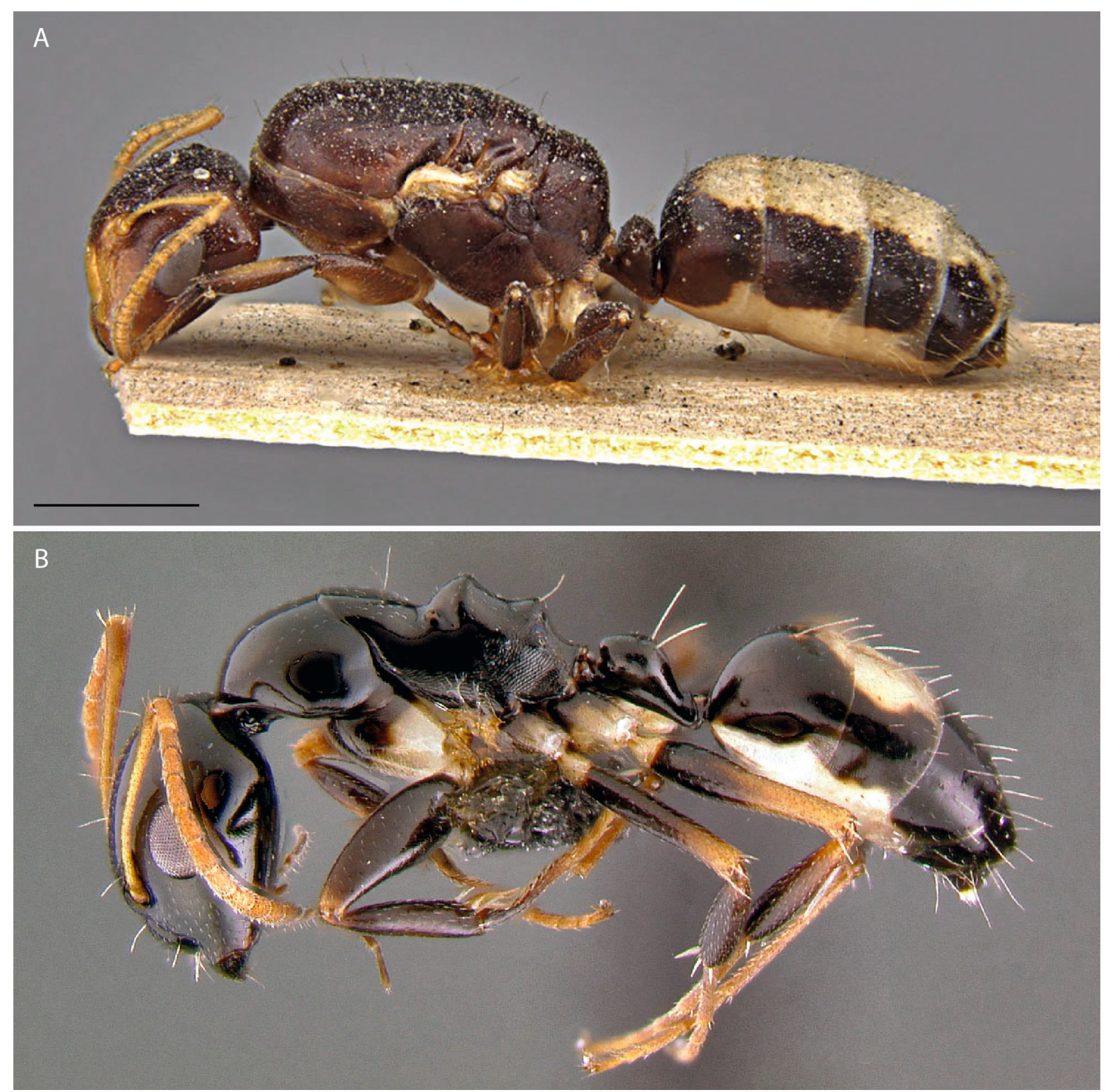

Figure 9. Camponotus leucodiscus, lateral view of body; scale bar for A =1.0 mm, no scale available for B. A: Holotype dealate queen (MCZ-ENT00021564), image from MCZbase (Museum of Comparative Zoology, Harvard University, copyright President and Fellows of Harvard College). B: worker, image from AntWiki (https://www.antwiki.org/wiki/File:Camponotus-bellus-leucodisc.jpg by Gary Alpert; used with Creative Commons CC 4.0).

sence of constriction between the third and fourth abdominal segments, and failure of the clypeus to extend between the antennal toruli, among other features (see subfamily key in Boudinot 2015). Given the available sample, male Camponotini are distinguishable from those of other formicine tribes by the following combination of traits (Fig. 10): (1) antennal toruli posteriorly-situated (i.e., anterior margins of torular rims distant from posterior clypeal margin); (2) antennae 13-merous; (3) arolia grossly enlarged; (4) gonostyli usually distinctly digitate (finger-like in shape and proportions); (5) waist simple, i.e., (5a) petiolar node usually vertical (except, e.g., $\mathrm{Ca}$. (Myrmopytia) longicollis, which lacks a node altogether), (5b) petiole is not elongate posteriorly (e.g., anterior and posterior faces of node subequal in length), (5c) ter- gosternal articulation of abdominal segment III (AIII) is unfused, (5d) AIII articulation not raised dorsally above helcium, and (5e) the anterior surface of abdominal tergum III is convex, without a median longitudinal groove for reception of the petiole when "gaster" flexed anteriorly; (6) in most species, the first free abscissae of the radial sector and media veins (Rsf1 and Mf1) are characteristically aligned, forming a more-or-less straight line, although they may be kinked at the juncture of Rs+M, or have some other curvature; in rare cases, e.g., Colobopsis pylora (alate gyne examined), the abscissae meet at a distinct angle; (7) fore wing crossvein $1 \mathrm{~m}$-cu is usually absent (although loss within the group may have occurred in parallel, see Remarks below); and (8) head with distinct shape, resembling an inverted pear in full-face 


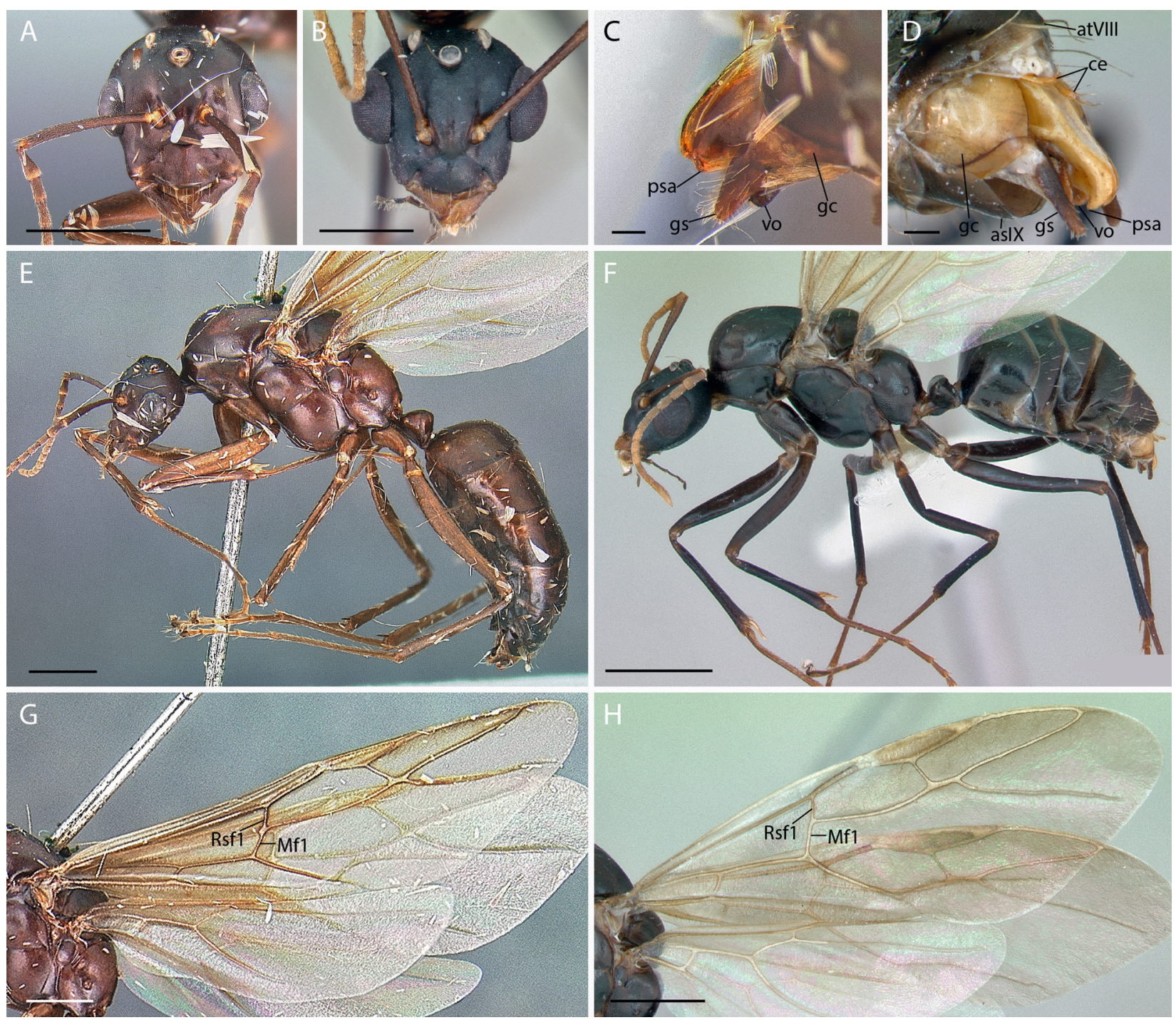

Figure 10. Habitus of male Colobopsis and Camponotus; (A, B) heads in full-face (dorsal) view; (C, D) genitalia in dorsolateral oblique view; $(\mathrm{E}, \mathrm{F})$ bodies in profile view; $(\mathrm{G}, \mathrm{H})$ wings in ventral view; scale bars: $\mathrm{A}, \mathrm{B}=0.5 \mathrm{~mm}, \mathrm{C}, \mathrm{D}=0.1 \mathrm{~mm}, \mathrm{E}-\mathrm{G}$ $=1.0 \mathrm{~mm}$. A, C, E, G: Colobopsis species indet., from Fijian radiation (CASENT0171201). B, D, F, H: Camponotus planus (CASENT0173220, image from AntWeb [www.antweb.org], photographed by April Nobile). Abbreviations: atVIII = abdominal tergum VIII (metasomal VII), asIX = abdominal sternum IX (metasomal VIII), ce = cerci, gc = gonocoxa, gs = gonostylus, Mf1 = first free medial vein abscissa, psa $=$ penial sclerite ventral apex, Rsf1 $=$ first free radial sector vein abscissa, vo $=$ volsella .

view: (8a) posterior head margin broadly convex, (8b) posterior head margin continuous or nearly so with the strongly bulging compound eyes (rarely the head is posteriorly elongate, e.g., Camponotus gouldi), (8c) malar area from the compound eyes to the mandibular insertion in full-face view strongly narrowed lateromedially, usually with parallel to subparallel malar margins that are almost orthogonal to the anterior eye margin.

Genera included. Calomyrmex Emery, Camponotus, Colobopsis, Dinomyrmex Ashmead, Echinopla F. Smith, Opisthopsis Dalla Torre, Overbeckia Viehmeyer, Polyrhachis $\mathrm{F}$. Smith.

Remarks on distinguishing the genera. Camponotus and Colobopsis are globally distinguished from one another in the key to males provided below (section 3.3.2), and are the only camponotine genera occurring in the
New World. In the Old World, these genera can be confused with Calomyrmex, Dinomyrmex, Echinopla, Opisthopsis, Overbeckia, or Polyrhachis, for which differentiating features are noted below. In general, Colobopsis is the only genus among these with antennal toruli situated at midlength of the frontal carinae, although some male Camponotus can be hard to evaluate due to poor development of the carinae. Further scrutiny of this condition is necessary.

Dinomyrmex males are readily identified by the following combination of states: (1) body massive, $2 \mathrm{~cm}$ long; (2) head oddly shaped, with concave malar regions in full-face view; (3) propodeal spiracles long, slit-shaped; (4) petiolar node broadly wedge-shaped in profile view; (5) gonapophyses lateromedially flattened and weakly lobate; (6) golden pubescence present on pronotum; and (7) numerous long, reddish macrosetae present on pronotum, lateral mesonotum, and propodeum. 

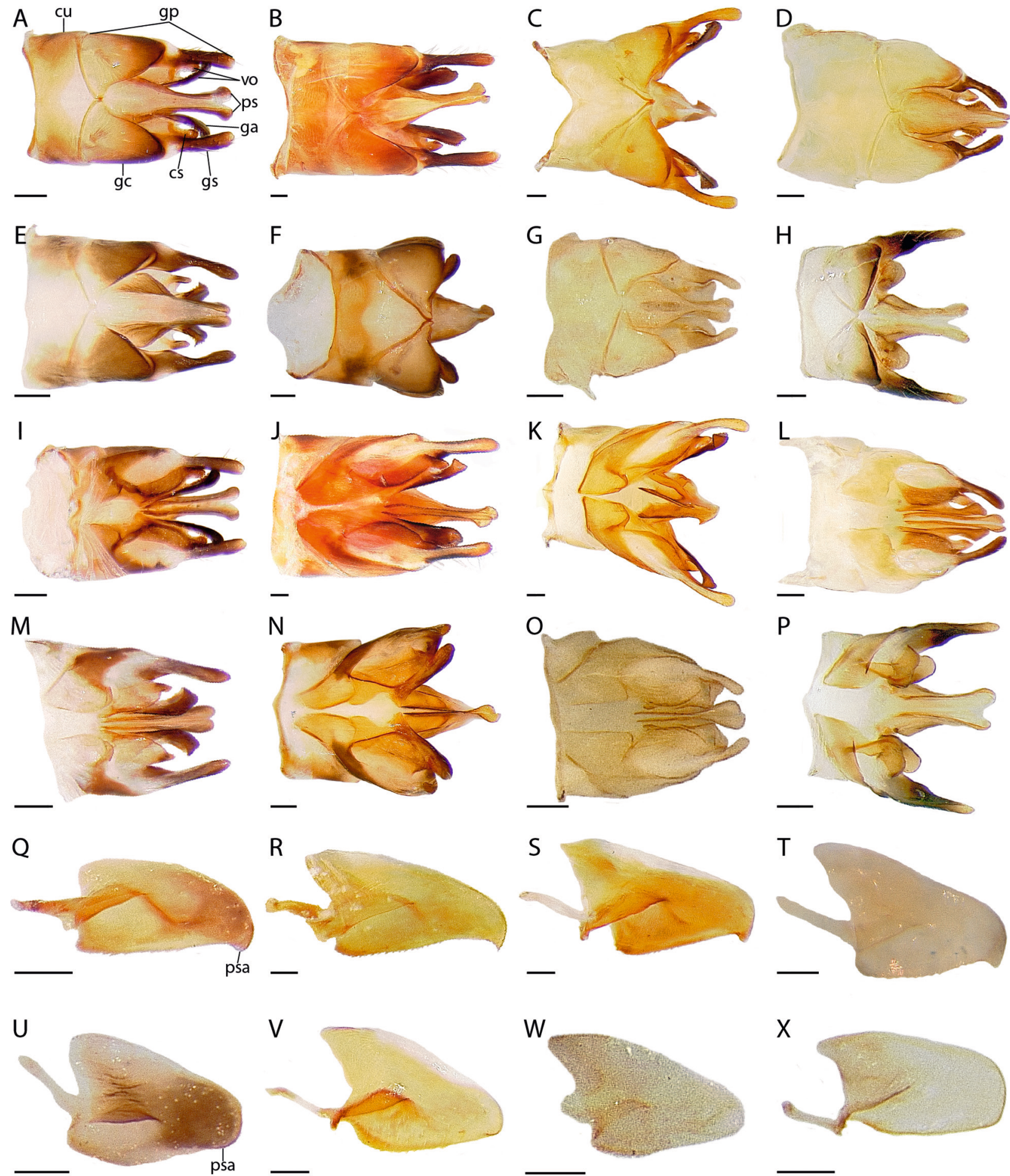

Figure 11. Comparison of male genitalia, with Camponotus $(\mathbf{A}-\mathbf{D}, \mathbf{I}-\mathbf{L}, \mathbf{Q}-\mathbf{T})$ and Colobopsis $(\mathbf{E}-\mathbf{H}, \mathbf{M}-\mathbf{P}, \mathbf{U}-\mathbf{X})$ in alternate rows, scale bars $=0.1 \mathrm{~mm}$. A-H, genital capsules dorsal view; $\mathbf{I}-\mathbf{P}$, genital capsules ventral view; $\mathbf{Q}-\mathbf{X}$, penial sclerites lateral view. A, I, Q, Camponotus (Mayria) species indet. (CASENT0844695). B, J, R, Camponotus (Tanaemyrmex) vicinus (CASENT0844696). C, K, S, Camponotus (Myrmostenus) mirabilis (CASENT0844697). D, L, T, Camponotus (Myrmotrema) bottegoi (CASENT0844698). E, M, U, Colobopsis gasseri (CASENT0844699). F, N, V, Colobopsis cylindrica group, species indet. (CASENT0844700). G, O, W, Colobopsis macrocephala (CASENT0844701). H, P, X, Colobopsis moeschi lygaea (CASENT0844702). Note: Q, R, T-W right penial sclerites, but images flipped for figure; penial apodeme of $\mathbf{W}$ broken during dissection. Abbreviations: $\mathrm{cu}=$ cupula, $\mathrm{cs}=$ cuspsis, $\mathrm{ga}=$ gonapophysis, $\mathrm{gc}=$ gonocoxa, $\mathrm{gp}=$ gonopod, $\mathrm{gs}=$ gonostylus, $\mathrm{ps}=$ penial sclerite, $\mathrm{psa}=$ penial sclerite ventral apex.

Polyrhachis is easily distinguished. Based on examination of a sample of males from nine of the 13 current valid Polyrhachis subgenera (Campomyrma Wheeler,
Chariomyrma Forel, Cyrtomyrma Forel, Hagiomyrma Wheeler, Hemioptica Roger, Myrma Billberg, Myrmatopa Forel, Myrmhopla Forel, Polyrhachis), the following 
differential characters were observed for the genus: (1) head posteriorly truncate in posterior/posterodorsal view, with the posteromedian margin carinate; (2) frontal carinae usually robust, especially broad dorsoventrally dorsal to medial torular arch as seen in lateral view (orientation assuming prognathy), and often strong and well-marked; (3) third abdominal tergum often $>1 / 3$ the total length of the gaster; and (4) helcial tergite elongate, with a very shallow notch or even an anteromedian lobe (e.g., in Polyrhachis sensu stricto), although the medial notch may be extremely long and narrow, reaching the helcial base, as in some Myrmatopa. None of the helcial states observed in Polyrhachis have been seen in Camponotus. While the genitalia and ninth abdominal sternum of Camponotus tend to be rather uniform, those of Polyrhachis vary considerably from species to species and subgenus to subgenus, in ways which are distinct from Camponotus and which deserve special attention.

The boundaries of Calomyrmex, Echinopla, Opisthopsis, and Overbeckia remain largely unexplored due to limited sampling. At least one species of Opisthopsis and one of Calomyrmex (in UCDC), and at least Colobopsis vitrea (male unknown) have the forewing crossvein 1m-cu enclosing and forming a discal cell. A discal cell is absent in Echinopla, Camponotus (including the recently demoted subgenus Phasmomyrmex), most Colobopsis, Overbeckia, and Polyrhachis. Opisthopsis (when 1m-cu present) and Calomyrmex (when $1 \mathrm{~m}-\mathrm{cu}$ present) may be distin- guished from one another by the shape of the discal cell, being isosceles-shaped in Opisthopsis and subrectangular in Calomyrmex; however, this should be validated with a broader taxonomic sample. The examined male of Opisthopsis, that of $O$. haddoni (MHNG), was observed to have an exceptionally sharp and long ventroapical point of the penial sclerite; this species also has small ocelli, a very shallow and short posterior head margin posterad the compound eyes, and a large and convex anterior clypeal lobe. Among Echinopla, only E. striata was available for examination; the male of this species lacks $1 \mathrm{~m}$-cu, has a short third abdominal tergum, has a posteriorly-truncate head as in Polyrhachis, and is extremely hairy with both standing pilosity and pubescence. The male of Overbeck$i a$ has short scapes which are shorter than the head length, very close-set antennal toruli (separated by slightly more than one torular diameter), a small clypeus without an anterior lobe, and a long head posterior to the compound eyes.

\subsubsection{Diagnostic key for Camponotus and Colobopsis males}

Note: Characters 3 and 4 of the key below are the most reliable, although the latter is complex and, based on experience, requires examination at multiple angles to fully comprehend.

1. Body features. (1) The mesonotum usually lacks macrosetae except for one or two pairs on mesoscutellum (global), infrequently with more (some Indomalayan species). (2) The propodeal spiracle is small, circular, pinprick-like, with certain species in Fiji being the only known exceptions. - Genital features. (3) The penial sclerite apex is rounded in lateral view, without an apicoventral tooth (Figs. 10C, 11U-X, psa). (4) Except for the cylindrica species group (Fig. 11N), the gonapophysis (= digitus) is scoop-shaped in anteroventral view, with the apex seeming "folded" laterally (Fig. 11M, O, P); the ventral margin of gonapophysis is sharply carinate, and the carina extends distally and curves laterodorsally just basal to gonapophyseal apex, dividing the apical portion of the gonapophysis into distinct proximal and distal faces; the apicolateral extension of the carina is sharply-defined. (5) The cuspis is fine, usually forming a transverse lobe (Fig. 11N-P), rarely digitate in ventral view (Fig. 11M). ........ Colobopsis

1' Body features. (1) The mesonotum usually bears several macrosetae (global), rarely with few (e.g., Ca. (Pseudocolobopsis) may have 1 seta pair). (2) The propodeal spiracle is variable in size and shape, from small and circular to large and slit-shaped. - Genital features. (3) The penial sclerite apex is hooked in lateral view, with a distinct apicoventral tooth (Figs. 10D, 11Q-T, psa) which may or may not be sharply pointed (the tooth may be poorly developed, as in Ca. (Dendromyrmex) nitidior, which overlaps with Colobopsis in Central America but is distinctive in shape and pilosity). (4) The form of the gonapophysis (= digitus) is variable, but always robust and club- or mace-shaped (Fig. 11I-L); when a sharp ventral carina is present, the carina continues apicolaterally as an obviously rounded ridge or tumosity, and does not extend to the apex of the digitus. (5) The cuspis is robust, usually digitiform in ventral view (Fig. 11I-L).

Camponotus

\section{Discussion and conclusion}

The two ant genera that are the subject of this study are ecologically prominent, species-rich, and widely distributed, collectively occupying much of the planet's terrestrial landscapes (Emery 1925, Bolton 1995, Fisher 2009). They are especially diverse in tropical regions, and undoubtedly have significant roles as predators, scavengers, and consumers of honeydew. Like other members of the tribe Camponotini, species of Camponotus and Colobopsis harbor obligate, vertically inherited endosymbionts (Blochmannia) that are believed to provide essential nutritional benefits to their ant hosts (Feldhaar et al. 2007, Wernegreen et al. 2009, Rafiqi et al. 2020).

Concomitant with the colonization of so many habitats, species of Camponotus and Colobopsis have undergone extensive morphological diversification. Certain 
Table 1. Summary of taxonomic changes in this paper. This includes novel subgenus placements; these are not new or revived combinations as defined by the ICZN.

\begin{tabular}{|c|c|c|}
\hline Taxon & Change & Notes \\
\hline Colobopsis moeschi & comb. nov. & Previously in Camponotus \\
\hline Colobopsis moeschi lygaea & comb. nov. & Previously in Camponotus \\
\hline Colobopsis nutans & comb. nov. & Previously in Camponotus \\
\hline Colobopsis nutans cleliae & comb. nov. & Previously in Camponotus \\
\hline Colobopsis reichenspergeri & comb. nov. & Previously in Camponotus \\
\hline Camponotus horrens & comb. rev. & Returned to Camponotus, from Colobopsis \\
\hline Camponotus politae & comb. rev. & Returned to Camponotus, from Colobopsis \\
\hline Camponotus aurelianus & comb. rev. & Returned to Camponotus, from Colobopsis \\
\hline Camponotus trajanus & comb. rev. & Returned to Camponotus, from Colobopsis \\
\hline Camponotus apostemata & comb. nov. & Previously in Colobopsis \\
\hline Camponotus cavibregma & comb. nov. & Previously in Colobopsis \\
\hline Camponotus yogi & comb. rev. & Returned to Camponotus, from Colobopsis \\
\hline Myrmotemnus & syn. nov. & Junior synonym of Colobopsis \\
\hline Dolophra & syn. rev. & Junior synonym of Camponotus \\
\hline Camponotus apostemata & syn. nov. & Junior synonym of Camponotus yogi \\
\hline Camponotus cavibregma & syn. nov. & Junior synonym of Camponotus yogi \\
\hline Camponotus quercicola & syn. nov. & Junior synonym of Camponotus laevigatus \\
\hline Camponotus adustus & stat. nov. & Previously subspecies of Camponotus bellus \\
\hline Camponotus leucodiscus & stat. rev. & Species status restored \\
\hline Camponotus hypoclineoides & subgenus & Restored to Camponotus (Karavaievia) \\
\hline Camponotus impressilabris & subgenus & Placed in Camponotus (Orthonotomyrmex) \\
\hline Camponotus horrens & subgenus & Placed in Camponotus (Myrmamblys) \\
\hline Camponotus politae & subgenus & Placed in Camponotus (Myrmamblys) \\
\hline Camponotus aurelianus & subgenus & Placed in Camponotus (Myrmamblys) \\
\hline Camponotus trajanus & subgenus & Placed in Camponotus (Myrmamblys) \\
\hline Camponotus apostemata & subgenus & Placed in Camponotus (Camponotus) \\
\hline Camponotus cavibregma & subgenus & Placed in Camponotus (Camponotus) \\
\hline Camponotus yogi & subgenus & Placed in Camponotus (Camponotus) \\
\hline Camponotus clarithorax & subgenus & Placed in Camponotus (Camponotus) \\
\hline
\end{tabular}

arboreal taxa have come to occupy similar morphospace, especially with respect to the cranial architecture of the major worker. Phragmotic heads, serving to block the entrances of twig nests, have evolved - to varying degrees-in multiple lineages of both Camponotus and Colobopsis (Fig. 1). Such convergent evolution delights the evolutionist, but can prove frustrating to the taxonomist. Here we have examined several problematic taxa that were given insufficient attention in an earlier treatment (Ward et al. 2016), and reevaluated their taxonomic placement. We depend largely on the morphological distinctions adduced in the previous study (Ward et al. 2016) because they were supported by complementary evidence from larva and pupal characters, and corroborated by robust phylogenetic inference from phylogenomic data (Blaimer et al. 2015).

Our investigations and taxonomic changes (summarized in Table 1) have refined our understanding of these ants, revealing for example that one putative subgenus of Camponotus, Myrmotemnus, is in fact a subgroup of Colobopsis. Our study highlights the need for greater taxonomic attention to the Camponotus reticulatus group (in subgenus Myrmamblys), several species of which had been placed incorrectly in Colobopsis. We were also able to demonstrate that several "Colobopsis" taxa recognized in a recent revision of the New World species of this genus belong to the genus Camponotus. With these reassignments we feel that the composition of the two genera has largely stabilized, setting the stage for more thorough comparative analyses of trait evolution in these ants.

In contrast to the scarcity (and potential fickleness) of diagnostic features in the worker caste, our investigation has revealed several promising features of male morphology - specifically male genitalia - that serve to distinguish Camponotus and Colobopsis. Although males are understudied in Formicidae, they yield consistent and surprising distinguishing features among subfamilies, genera, and species groups (e.g., Ward 1999, Ward and Downie 2005, Boudinot 2015, Barden et al. 2017). Males may be less prone to homoplasy than workers and queens because they are not subject to the same ecological pressures due to their hermitic lifestyles. Moreover, the male genitalia of ants are complex copulatory machines which display considerable functional morphological variation. In some cases, the male genitalia appear to have undergone sexually-selected runaway evolution as observed 
in lineages such as the army ants (Old and New World), spider ants (Leptomyrmex), castrator ants (Diacamma), fungus-growing ants (Atta genus group), and legionary vampire ants (Leptanillinae). Among the examined camponotines, Colobopsis is uniquely defined by the synapomorphic loss of the apicoventral tooth of the penial sclerite, which implies concomitant behavioral derivation during copulation. We hope that the dissections figured in the present work encourage future studies of camponotine genitalia. With reciprocal illumination from burgeoning phylogenomic studies, the exploration of morphological variation in male, worker, and queen ants will inform our understanding of phylogeny and evolution for many years to come.

\section{Authors' contributions}

Concept and execution: PSW and BEB. Worker taxonomy: PSW. Male morphology: BEB.

\section{Acknowledgements}

We thank the following curators for access to material in the indicated collections: Dave Grimaldi, Christine Lebeau, and Courtney Richenbacher (AMNH), Barry Bolton and Suzanne Ryder (BMNH), Brian Fisher (CASC), Jacques Delabie (CPDC), Kevin Williams and Martin Hauser (CSCA), Rodrigo Feitosa (DZUP), Silvia Lobo (INBC), Marcio Oliveira and Itanna Fernandes (INPA), Jack Longino (JTLC), Roy Snelling, Brian Brown and Weiping Xie (LACM), Stefan Cover (MCZC), Bernard Landry (MHNG), Marek Borowiec (MLBC), Maria Tavano (MSNG), Roberto Brandão (MZSP), Herbert Zettel (NHMW), and Ted Schultz and Eugenia Okonski (USNM). We also thank Melissa Lynne, Museum of Comparative Zoology, Harvard University, for providing permission to use three images from MCZBase. We are especially grateful to the curators of AntWeb (Brian Fisher, Michele Esposito, and collaborators) for making freely available to the public a vast store of images and information about ants. This site and AntCat (www.antcat.org) are the most valuable online resources for ant taxonomy. We are grateful to Brad Sinclair and two anonymous reviewers for helpful comments that improved the manuscript. This research was supported by NSF grants DEB-1856571 and DEB-1932405 to PSW. BEB gratefully acknowledges two formative Ernst Mayr Grants from the Museum of Comparative Zoology (2013, 2016) and support from the Alexander von Humboldt Stiftung.

\section{References}

Barden P, Boudinot B, Lucky A (2017) Where fossils dare and males matter: combined morphological and molecular analysis untangles the evolutionary history of the spider ant genus Leptomyrmex Mayr (Hymenoptera: Dolichoderinae). Invertebrate Systematics 31: 765780. https://doi.org/10.1071/IS16067
Birket-Smith SJR (1981) The male genitalia of Hymenoptera - a review based on morphology in Dorylidae (Formicoidea). Entomologica Scandinavia Supplementum 15: 377-397.

Blaimer BB, Brady SG, Schultz TR, Lloyd MW, Fisher BL, Ward PS (2015) Phylogenomic methods outperform traditional multi-locus approaches in resolving deep evolutionary history: a case study of formicine ants. BMC Evolutionary Biology 15: 271. https://doi.org/ 10.1186/s12862-015-0552-5

Blanchard BD, Moreau CS (2017) Defensive traits exhibit an evolutionary trade-off and drive diversification in ants. Evolution 71 : 315-328. https://doi.org/10.1111/evo.13117

Bolton B (1995) A new general catalogue of the ants of the world. Harvard University Press, Cambridge, Massachusetts, $504 \mathrm{pp}$

Bolton B (2003) Synopsis and classification of Formicidae. Memoirs of the American Entomological Institute 71: 1-370.

Borowiec ML (2019) Convergent evolution of the army ant syndrome and congruence in big-data phylogenetics. Systematic Biology 68: 642-656. https://doi.org/10.1093/sysbio/syy088

Boudinot B (2013) The male genitalia of ants: musculature, homology, and functional morphology (Hymenoptera, Aculeata, Formicidae). Journal of Hymenoptera Research 30: 29. https://doi.org/10.3897/ jhr.30.3535

Boudinot BE (2015) Contributions to the knowledge of Formicidae (Hymenoptera, Aculeata): a new diagnosis of the family, the first global male-based key to subfamilies, and a treatment of early branching lineages. European Journal of Taxonomy. https://doi.org/ 10.5852/ejt.2015.120

Boudinot BE (2018) A general theory of genital homologies for the Hexapoda (Pancrustacea) derived from skeletomuscular correspondences, with emphasis on the Endopterygota. Arthropod Structure \& Development 47: 563-613. https://doi.org/10.1016/j.asd. 2018.11.001

Brown WL, Nutting WL (1950) Wing venation and the phylogeny of the Formicidae (Hymenoptera). Transactions of the American Entomological Society 75: 113-132.

Clouse RM, Janda M, Blanchard B, Sharma P, Hoffmann BD, Andersen AN, Czekanski-Moir JE, Krushelnycky P, Rabeling C, Wilson EO (2015) Molecular phylogeny of Indo-Pacific carpenter ants (Hymenoptera: Formicidae, Camponotus) reveals waves of dispersal and colonization from diverse source areas. Cladistics 31: 424-437. https://doi.org/10.1111/cla.12099

Creighton WS, Snelling RR (1967) The rediscovery of Camponotus (Myrmaphaenus) yogi Wheeler (Hymenoptera: Formicidae). Psyche (Cambridge) 73: 187-195.

Dumpert K, Maschwitz U, Weissflog A (2006) Description of five new weaver ant species of Camponotus subgenus Karavaievia Emery, 1925 (Hymenoptera: Formicidae) from Malaysia and Thailand, with contribution to their biology, especially to colony foundation. Myrmecologische Nachrichten 8: 69-82.

Emery C (1925) Hymenoptera, Fam. Formicidae, subfam. Formicinae. Genera Insectorum 183: 1-302.

Feldhaar H, Straka J, Krischke M, Berthold K, Stoll S, Mueller MJ, Gross R (2007) Nutritional upgrading for omnivorous carpenter ants by the endosymbiont Blochmannia. BMC Biology 5: 1-11. https:// doi.org/10.1186/1741-7007-5-48

Fisher BL (2009) Biogeography. In: Lach L, Parr C, Abbott K (Eds), Ant Ecology. Oxford University Press, Oxford, 18-37.

Forel A (1910) Fourmis des Philippines. Philippine Journal of Science. Section D. General Biology, Ethnology and Anthropology 5: 121130. 
Forel A (1914) Le genre Camponotus Mayr et les genres voisins. Revue Suisse de Zoologie 22: 257-276.

Gadau J, Brady SG, Ward PS (1999) Systematics, distribution, and ecology of an endemic California Camponotus quercicola (Hymenoptera: Formicidae). Annals of the Entomological Society of America 92: 514-522. https://doi.org/10.1093/aesa/92.4.514

Harris RA (1979) A glossary of surface sculpturing. California Department of Food and Agriculture, Bureau of Entomology, Occasional Papers in Entomology 28: 1-31.

Hennig W (1957) Systematik und Phylogenese. In: Hannemann H-J (Ed.), Bericht über die Hundertjahrfeier der Deutschen Entomologischen Gesellschaft Berlin. Akademie Verlag, Berlin, 50-71.

Hermann HR, Blum MS (1981) Defensive mechanisms in the social Hymenoptera. In: Hermann HR (Ed.), Social Insects. Academic Press, New York, 77-197.

Hölldobler B, Wilson EO (1990) The ants. Harvard University Press, Cambridge, Massachusetts, 732 pp.

Johnson RA, Ward PS (2002) Biogeography and endemism of ants (Hymenoptera: Formicidae) in Baja California, Mexico: a first overview. Journal of Biogeography 29: 1009-1026. https://doi.org/10.1046/ j.1365-2699.2002.00746.x

Kempf WW (1956) A morphological study on the male genitalia of Paracryptocerus (P.) pusillus (Hymenoptera: Formicidae). Revista Brasileira de Entomologia 17: 395-404.

Klimes P, McArthur A (2014) Diversity and ecology of arboricolous ant communities of Camponotus (Hymenoptera: Formicidae) in a New Guinea rainforest with descriptions of four new species. Myrmecological News 20: 141-158.

Laciny A, Zettel H, Kopchinskiy A, Pretzer C, Pal A, Salim KA, Rahimi MJ, Hoenigsberger M, Lim L, Jaitrong W (2018) Colobopsis explodens sp. n., model species for studies on "exploding ants" (Hymenoptera, Formicidae), with biological notes and first illustrations of males of the Colobopsis cylindrica group. ZooKeys 751: 1-40 https://doi.org/10.3897/zookeys.751.22661

Liu S-P, Richter A, Stoessel A, Beutel RG (2019) The mesosomal anatomy of Myrmecia nigrocincta workers and evolutionary transformations in Formicidae (Hymenoptera). Arthropod Systematics \& Phylogeny 77: 1-19. https://doi.org/10.26049/ASP77-1-2019-01

Mackay WP (2019) New World carpenter ants of the hyperdiverse genus Camponotus. Volume 1. Introduction, keys to the subgenera and species complexes and the subgenus Camponotus. Lambert Academic Publishing, Mauritius, 412 pp.

Mackay WP, Mackay EE (2018) Revision of the New World cork-headed ants of the genus Colobopsis. Lambert Academic Publishing, Mauritius, $279 \mathrm{pp}$.

Mayr GL (1861) Die Europäischen Formiciden: nach der analytischen Methode bearbeitet. C. Gerolds Sohn, Vienna, Austria, 80 pp.

Prebus M (2017) Insights into the evolution, biogeography and natural history of the acorn ants, genus Temnothorax Mayr (hymenoptera: Formicidae). BMC Evolutionary Biology 17: 1-22. https://doi.org/ 10.1186/s12862-017-1095-8

Rabeling C, Schultz TR, Pierce NE, Bacci Jr M (2014) A social parasite evolved reproductive isolation from its fungus-growing ant host in sympatry. Current Biology 24: 2047-2052. https://doi.org/10.1016/j. cub.2014.07.048

Rafiqi AM, Rajakumar A, Abouheif E (2020) Origin and elaboration of a major evolutionary transition in individuality. Nature 585: 239244. https://doi.org/10.1038/s41586-020-2653-6

Richter A, Keller RA, Rosumek FB, Economo EP, Garcia FH, Beutel RG (2019) The cephalic anatomy of workers of the ant species
Wasmannia affinis (Formicidae, Hymenoptera, Insecta) and its evolutionary implications. Arthropod Structure \& Development 49: 26-49. https://doi.org/10.1016/j.asd.2019.02.002

Richter A, Garcia FH, Keller RA, Billen J, Economo EP, Beutel RG (2020) Comparative analysis of worker head anatomy of Formica and Brachyponera (Hymenoptera: Formicidae). Arthropod Systematics \& Phylogeny 78: 133-170. https://doi.org/10.26049/ ASP78-1-2020-06

Roger J (1863) Verzeichniss der Formiciden-Gattungen und Arten. Berliner Entomologische Zeitschrift (Beilage) 7: 1-65

Santschi F (1926) Nouvelles notes sur les Camponotus. Revue Suisse de Zoologie 33: 597-618.

Schmidt C (2013) Molecular phylogenetics of ponerine ants (Hymenoptera: Formicidae: Ponerinae). Zootaxa 3647: 201-250. http://dx. doi.org/10.11646/zootaxa.3647.2.1

Schmidt C, Shattuck SO (2014) The higher classification of the ant subfamily Ponerinae (Hymenoptera: Formicidae), with a review of ponerine ecology and behavior. Zootaxa 3817: 1-242. https://doi. org/10.11646/zootaxa.3817.1.1

Schulmeister S (2001) Functional morphology of the male genitalia and copulation in lower Hymenoptera, with special emphasis on the Tenthredinoidea s. str. (Insecta, Hymenoptera, 'Symphyta'). Acta Zoologica 82: 331-349. https://doi.org/10.1046/j.1463-6395.2001.00094.x

Simpson GL (1953) The major features of evolution. Columbia University Press, New York, 434 pp.

Smith F (1858) Catalogue of hymenopterous insects in the collection of the British Museum. Part VI. Formicidae. British Museum, London, 216 pp.

Smith MR (1954) A new Camponotus in California apparently inhabiting live oak, Quercus sp. (Hymenoptera, Formicidae). Journal of the New York Entomological Society 61: 211-214.

Snodgrass RE (1941) The male genitalia of Hymenoptera. Smithsonian Miscellaneous Collections 99: 1-86.

Snodgrass RE (1957) A revised interpretation of the external reproductive organs of male insects. Smithsonian Miscellaneous Collections 135: $1-60$.

Viehmeyer H (1916) Ameisen von Singapore. Beobachtet und gesammelt von H. Overbeck. Archiv für Naturgeschichte (A) 81: 108-168.

Ward PS (1999) Systematics, biogeography and host plant associations of the Pseudomyrmex viduus group (Hymenoptera: Formicidae), Triplaris-and Tachigali-inhabiting ants. Zoological Journal of the Linnean Society 126: 451-540. https://doi. org/10.1111/j.1096-3642.1999.tb00157.x

Ward PS (2011) Integrating molecular phylogenetic results into ant taxonomy. Myrmecological News 15: 21-29.

Ward PS, Downie DA (2005) The ant subfamily Pseudomyrmecinae (Hymenoptera: Formicidae): phylogeny and evolution of big-eyed arboreal ants. Systematic Entomology 30: 310-335. https://doi. org/10.1111/j.1365-3113.2004.00281.x

Ward PS, Blaimer BB, Fisher BL (2016) A revised phylogenetic classification of the ant subfamily Formicinae (Hymenoptera: Formicidae), with resurrection of the genera Colobopsis and Dinomyrmex. Zootaxa 4072: 343-357. https://doi.org/10.11646/zootaxa.4072.3.4

Ward PS, Brady SG, Fisher BL, Schultz TR (2015) The evolution of myrmicine ants: phylogeny and biogeography of a hyperdiverse ant clade (Hymenoptera: Formicidae). Systematic Entomology 40: 61-81. https://doi.org/10.1111/syen.12090

Wernegreen JJ, Kauppinen SN, Brady SG, Ward PS (2009) One nutritional symbiosis begat another: Phylogenetic evidence that the ant tribe Camponotini acquired Blochmannia by tending sap-feed- 
ing insects. BMC Evolutionary Biology 9: 292. https://doi.org/ 10.1186/1471-2148-9-292

Wheeler WM (1915) Some additions to the North American ant-fauna. Bulletin of the American Museum of Natural History 34: 389-421.

Wheeler WM (1917) The mountain ants of western North America. Proceedings of the American Academy of Arts and Sciences 52: 457-569.

Wheeler WM (1919) The ants of Borneo. Bulletin of the Museum of Comparative Zoology 63: 43-147.

Wilson EO (1955) A monographic revision of the ant genus Lasius. Bulletin of the Museum of Comparative Zoology 113: 1-21.

Wu J, Wang C (1994) A new genus of ants from Yunnan, China (Hymenoptera: Formicidae: Formicinae). Journal of Beijing Forestry University (English Edition) 3: 35-38. 